\title{
O TELEMARKETING E O PERFIL SÓCIO-OCUPACIONAL DOS EMPREGADOS EM CALL CENTERS
}

\author{
Daniel Gustavo Mocelin * \\ Luís Fernando Santos Corrêa da Silva*
}

\begin{abstract}
Este artigo traz resultados de pesquisa sobre trabalhadores de um call center, em Porto Alegre, buscando analisar combinadamente como se trabalha e quem trabalha em atividades de telemarketing. Os call centers são organizações empresariais de prestação de serviços de telemarketing. Seus operadores são trabalhadores com escolarização elevada, frente aos níveis do mercado de trabalho brasileiro, o que apontaria para uma profissionalização da atividade. Paradoxalmente, as condições de trabalho, caracterizadas pela intensificação do trabalho e baixa remuneração, mas com exigência de qualificação média, influenciam as estratégias e os sentidos desse emprego para jovens trabalhadores, acabando por defini-lo como "emprego trampolim”, que responde apenas a uma superação transitória da condição material e simbólica e não a busca de profissionalização e estabilidade, mesmo com as exigências de conhecimentos técnicos especializados e reciclagem constante. As características do setor e a emergência desse novo tipo de trabalhador auxiliam compreender o trabalho no setor de serviços. Palavras-Chave: Sociologia do Trabalho, call centers Porto Alegre, perfil sócio-ocupacional de trabalhadores, rotatividade do emprego, serviços.
\end{abstract}

O telemarketing é a atividade desempenhada pelos empregados em call centers, situando-se entre as ocupações que mais geraram empregos nos últimos anos. Nas análises recentes, aponta-se para uma tendência de não-profissionalização dos empregados nesse tipo de atividade laboral, devido ao pouco tempo de permanência desses trabalhadores no emprego, o que se refletiria, inclusive, em baixa taxa de sindicalização.

Essas considerações têm constituído um paradoxo, uma vez que se observa serem os operadores de telemarketing trabalhadores com escolarização elevada frente aos níveis gerais do mercado de trabalho no Brasil, o que poderia apontar para certo grau de profissionalização nessa atividade. Contudo, o perfil sócio-ocupacional dos operadores de telemarketing não segue o padrão

* Doutorando em Sociologia pela Universidade Federal do Rio Grande do Sul. Integra o grupo de pesquisa sobre Trabalho na Sociedade Contemporânea da UFRGS.

Av. Bento Gonçalves, 9.500 - Campus do Vale, IFCH, Prédio 43311, sala 103. Bairro Agronomia. Cep: 90501.900. PortoAlegre - RS - Brasil. dmocelin@terra.com.br

* * Doutorando em Sociologia pela Universidade Federal do Rio Grande do Sul. Integra o grupo de pesquisa sobre Trabalho na Sociedade Contemporânea da UFRGS. lfscorrea@hotmail.com das atividades em que os trabalhadores estão mais organizados, como nas empresas de setores tradicionais, nem mesmo segue o padrão do mercado de trabalho em geral, apresentando especificidades vinculadas à natureza do trabalho executado em call centers e às aspirações dos trabalhadores, com perfil mais arrojado do que o regularmente verificado no mercado de trabalho.

Esse tipo de ocupação apresenta não apenas a tendência a um alto grau de rotatividade no emprego, resultante não só das baixas remunerações, mas também caracteriza um contingente de trabalhadores com baixa média de idade e com escolaridade relativamente elevada e (ou) escolarização crescente.

A atividade de telemarketing tem se caracterizado como uma ocupação no sentido preciso do termo: os trabalhadores estão nesses empregos "temporariamente", e os call centers têm se constituído como empresas de passagem. Essa seria uma tendência que tem perpassado a realidade do telemarketing, 
mesmo quando se observam diferentes condições de emprego, segundo o tipo ou a forma da atividade de telemarketing, que se distingue entre empresas e, às vezes, no interior de uma mesma empresa. Nesse sentido, o trabalho de telemarketing parece caracterizar um emprego trampolim. ${ }^{1}$

O objetivo do presente estudo é buscar revelar elementos que comprovem essa tese. Para tanto, são analisados características do conteúdo da atividade do telemarketing, associadas ao perfil dos trabalhadores empregados em call centers e às condições de trabalho e emprego oferecidas nessas atividades laborais.

Estudos no campo da Sociologia do trabalho (Castells, 1999; Batt, 2000; Kovács, 2001; Cattani, 2002; Larangeira, 1998, 2003) constataram, nas últimas três décadas, a constituição de um paradigma socioeconômico distinto do tayloristafordista. Com as mudanças ocorridas no contexto da organização do trabalho, desde então, novos perfis sócio-ocupacionais têm surgido, diferenciados dos perfis tradicionais tanto em termos de como se trabalha como de quem trabalha. Efetivamente, as mudanças no trabalho, bem como no emprego, resultam de transformações no padrão tecnológico da base produtiva, na dinâmica econômica, nas formas de gestão das empresas, na estrutura do mercado de trabalho e na emergência de novos tipos de ocupações.

Muitos dos empregos típicos da atualidade se distinguem do modelo de emprego predominante que marcou o período compreendido entre o pós-guerra e a década de 1970. Entretanto, essa distinção não seria apenas um reflexo de mudanças organizacionais, mas também seria produzida pela mudança do perfil e das aspirações pessoais e profissionais dos trabalhadores. Há um conjunto de características desses empregos da atualidade: instabilidade, baixos salários, achatamento da

${ }^{1}$ A acepção do conceito "emprego trampolim" contou com a colaboração do bolsista de iniciação científica Elvis Vitoriano da Silva. Deve-se destacar que trabalhos sobre esse tema foram apresentados no XII Congresso Brasileiro de Sociologia, realizado em Belo Horizonte, bem como no II Simpósio Internacional sobre Juventude Brasileira, realizado na Pontifícia Universidade Católica do Rio Grande do Sul. estrutura hierárquica, polivalência e heterogeneidade da mão-de-obra. Em sua maioria, tais empregos demandariam dos trabalhadores maiores competências tanto em termos de qualificação pessoal como de escolaridade formal. Porém, em muitos casos, não há uma contrapartida ou recompensa pelo maior grau de exigências das atividades laborais. Defrontados com essa realidade do trabalho, segmentos da população têm reagido a ela de diferentes maneiras: enquanto alguns sofreriam com as mudanças nas condições de emprego, outros produziriam novas estratégias de inserção profissional.

Nesse contexto, o setor de telecomunicações foi um dos mais marcados pelas transformações desencadeadas nas últimas décadas. Em quase todos os países do mundo, observou-se a reestruturação do setor, movida, sobretudo, por inovações tecnológicas que alteraram sua lógica funcional e organizacional, com impactos importantes sobre o perfil dos empregados. A digitalização das redes de comunicação, o desenvolvimento da Internet, a invenção da telefonia móvel, entre outros, foram inovações que poderiam ser exploradas de forma bastante lucrativa. Desse modo, observa-se o fim dos monopólios, privados ou estatais, que haviam caracterizado o funcionamento do setor até então, abrindo esse mercado para as empresas privadas segundo a perspectiva da exploração dos serviços, da concorrência e do atendimento a novas demandas sociais, muito mais heterogêneas (Larangeira, 1998, 2003).

No contexto da reestruturação das empresas de telecomunicação, as atividades de tele-atendimento, responsáveis pelo contato com o cliente por via telefônica, mas também por e-mail e fax, e que, antes da extinção dos monopólios, eram partes das empresas de telecomunicações, foram externalizadas, ainda que a maior parte dessas empresas seja de propriedade das próprias empresas de telecomunicações. Denominadas de call centers, as novas empresas de telemarketing integram tecnologia e recursos humanos, combinando telecomunicações e informática, para processar tráfego de chamadas telefônicas e administrar o rela- 
Daniel Gustavo Mocelin,

Luís Fernando Santos Corrêa da Silva

cionamento entre uma empresa e seus clientes.

Os call centers assumem posição central no novo cenário desenhado para o setor de telecomunicações, mas também para praticamente todos os outros setores econômicos. No caso do setor de telecomunicações, essas empresas não apenas empregariam cerca de 40 a $50 \%$ do contingente de trabalhadores, como também seriam, no âmbito comercial, fundamentais para a constituição de vantagens competitivas entre elas, considerando que o telemarketing seria responsável pelo contato com o cliente, promovendo vendas de serviços, oferta de planos de consumo e fidelização. Um melhor atendimento poderia contribuir na prospecção de novos clientes e na manutenção dos atuais na carteira de prestação de serviços das empresas de telecomunicações.

Parte da expansão dos serviços de call center decorre do crescimento do acesso aos serviços de telecomunicações, o que tem resultado na expansão de novas formas de contato e relacionamento entre empresas de telefonia, televisão por cabo e provedores de Internet e seus clientes, substituindo o atendimento face a face. Nesse contexto, os call centers têm ocupado lugar destacado como ferramentas para gerenciar o contato e o relacionamento a partir de novos canais de interação e comunicação. No âmbito empresarial, os call centers seriam também uma ferramenta competitiva, considerando a sua potencialidade, abrangência e custo baixo.

\section{DESAFIOS À CONTEXTUALIZAÇÃO DO TRABALHO EM CALL CENTERSE ATIVIDA- DES DE TELEMARKETING}

Nos dias de hoje, muitos estudiosos discutem mudanças nas formas de organização do trabalho. Para Castells (1999), as novas tecnologias de informação teriam lançado as bases para o desaparecimento das tarefas rotineiras e repetitivas, normalmente relacionadas ao paradigma tayloristafordista de organização do trabalho, sobretudo nos grandes centros capitalistas, visto que, nos países em fase de industrialização, o taylorismo tenderia a permanecer vigente. Nas empresas características da sociedade informacional, a execução das tarefas que envolvem atividades repetitivas ficaria a cargo de equipamentos pré-programados e précodificados, dispensando, dessa forma, o trabalho humano.

Segundo Kovács (2001), haveria três perspectivas para a interpretação das transformações organizacionais decorrentes do processo de reestruturação por que passaram as empresas capitalistas, após a década de 1980. A primeira acredita na emergência de um novo tipo de economia, marcado pelo paradigma pós-taylorista-fordista, em que o conhecimento, a flexibilidade e a utilização de novas tecnologias ocupariam espaço central. A segunda afirma que o modelo taylorista-fordista permaneceria ocupando o papel de modelo econômico dominante. A terceira perspectiva configurar-se-ia a partir da combinação dos dois modelos citados, em que as formas de organização das empresas e do processo de trabalho estariam segmentadas de acordo com o ambiente social, coexistindo em vários contextos, em âmbito nacional, setorial, ou no interior de uma mesma empresa (2001).

Sob tais condições, discutem-se as formas de organização do trabalho e as vantagens da tecnologia da informação no setor de serviços (Batt, 2000).

A estratégia “low road", similar à produção de massa na indústria, estaria ancorada na utilização da tecnologia (automação de processos) para substituir trabalhadores não-qualificados e proceder ao monitoramento de desempenho, na busca de alto volume e baixos custos de produção. A organização do trabalho conduziria à padronização e à racionalização de tarefas, permitindo o recrutamento de trabalhadores com baixa qualificação (2000).

Por sua vez, a estratégia alternativa, denominada de "high road", ou modelos participativos, possuiria como princípio o recrutamento de empregados mais qualificados, com treinamento especializado, utilização inteligente da tecnologia e relativa autonomia de negociação com o cliente ou consumidor, o que os proveria de maiores responsabilidades, tendo em vista oferecer qualidade e 
personalização dos serviços. A organização do trabalho tenderia a valorizar formas participativas, buscando construir uma relação duradoura com os clientes ou consumidores. O pressuposto seria de que tal relação conduziria ao crescimento de vendas de serviços (bridging to sales) e, portanto, a uma maior lucratividade (Batt, 2000).

A atividade de telemarketing e os call centers parecem configurar um desafio analítico para as mais diversas questões teóricas antes citadas, pois, nessas empresas, seria executado um trabalho parcelado, mas que exige qualificações. Supõe-se que, nelas, esteja se constituindo um nicho ocupacional híbrido: por um lado, um trabalho parcelado e, por outro, trabalhadores qualificados ou em processo de qualificação. Nesse sentido, hipoteticamente, supõe-se que as atividades de telemarketing configurariam empregos-trampolim, ou seja, postos de trabalho temporariamente ocupados pelos trabalhadores, mas que não são atrativos profissionalmente, sendo descartados quando eles encontram uma melhor oportunidade ou concluem seus estudos, sua formação ou sua graduação.

Alguns estudiosos defendem que muitas dessas atividades estariam associando o trabalho repetitivo e intenso com as habilidades de comunicação, exigindo trabalhadores qualificados para tarefas repetitivas. As atividades de telemarketing e o trabalho em call centers seriam objetos privilegiados de investigação de estudos que defendem tal tese (Venco, 1999; Oliveira, 2004; Braga, 2006, 2007; Rosenfield, 2007a, 2007b). As abordagens dessa natureza são importantes, pois evidenciam as contradições que emergem da situação atual do trabalho e do emprego no âmbito da sociedade informacional, no Brasil. Porém, igualmente importante seria abordar a atividade de telemarketing sob a perspectiva dos trabalhadores, examinandose como esses atores sociais desenvolvem estratégias na tentativa de superar crises e dificuldades, na busca por novas oportunidades e novos cenários de mobilização.

Neste artigo, argumenta-se que a perspectiva acima referida não seria suficiente para compreender a realidade das atividades de telemarketing.
Equivocam-se os que concluem generalizadamente que o trabalho em call centers seria precário, pois negam a complexidade envolvida na questão, tanto na perspectiva dos trabalhadores que estão empregados nas atividades de telemarketing quanto na da heterogeneidade da organização do trabalho nos call centers. A perspectiva mencionada não leva em consideração, por exemplo, quem trabalha em call centers. Deixando de incorporar essa dimensão, os estudos perdem parte da capacidade de constatar elementos importantes, como as aspirações profissionais e os desejos dos trabalhadores, que nem sempre dizem respeito diretamente apenas às condições de trabalho e de emprego.

O presente estudo detém-se na definição de alguns aspectos relativos à atividade de telemarketing e ao perfil sócio-ocupacional dos empregados em call centers. O estudo desenvolve-se sobre dois eixos de análise, como se trabalha e quem trabalha nas empresas de call center, apresentando dados de uma pesquisa realizada em uma operadora de call center ligada a empresas de telecomunicações de Porto Alegre, confrontandoos com dados sobre a ocupação, definida por operadores de telemarketing, segundo a Classificação Brasileira de Ocupações ${ }^{2}$ (CBO, 2002), obtidos na Relação Anual de Informações Sociais ${ }^{3}$ do Ministério do Trabalho e Emprego do Brasil (MTE).

O interesse da pesquisa é contribuir para a compreensão de uma nova atividade que tem gran-

${ }^{2}$ É o documento normalizador do reconhecimento, da nomeação e da codificação dos títulos e conțeúdos das ocupações do mercado de trabalho brasileiro. É, ao mesmo tempo, uma classificação enumerativa e uma classificação descritiva. Como classificação enumerativa, ela codifica empregos e outras situações de trabalho para fins estatísticos de registros administrativos, censos populacionais e outras pesquisas domiciliares. Inclui códigos e títulos ocupacionais com sua descrição sumária. Ela também é conhecida pelos nomes de nomenclatura ocupacional e estrutura ocupacional. Como classificação descritiva, ela inventaria detalhadamente as atividades realizadas no trabalho, os requisitos de formação e experiência profissionais e as condicões de trabalho. Ministério do Trabalho e Emprego; Disponível em: www.mtecbo.gov.br/informação - Acesso em: 31 ago., 2006.

3 A Relação Anual de Informações Sociais (RAIS), instituída em 1975, fornece informações estatísticas sobre o mercado de trabalho formal no Brasil, funcionando em conjunto com o Cadastro Geral de Empregados e Desempregados (Caged), criado em 1965, que instituiu o registro permanente de admissões e dispensa de empregados; são mantidos pelo Ministério do Trabalho e Emprego. As bases estatísticas podem ser acessadas em www.mte.gov.br, mediante cadastro como pesquisador. 
Daniel Gustavo Mocelin,

Luís Fernando Santos Corrêa da Silva

de potencial na geração de emprego, ocupando posição de destaque em termos de quantidade de empregos gerados.

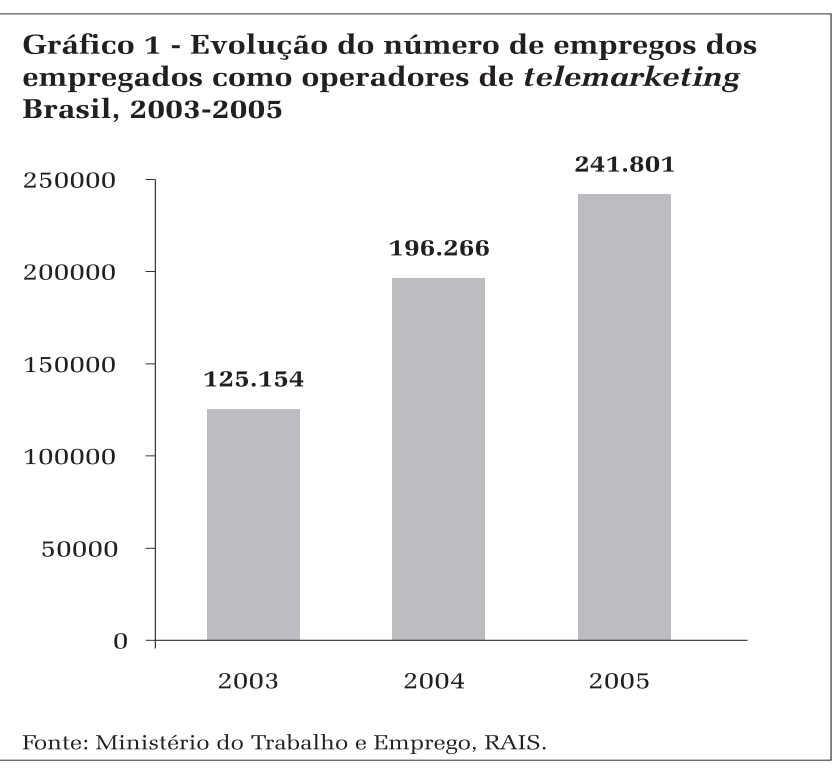

binem tanto a natureza e a heterogeneidade das atividades laborais realizadas nessas empresas, quanto às características das práticas de trabalho vinculadas ao telemarketing, bem como os perfis sócio-ocupacionais predominantes nesse contingente de trabalhadores.

Cabe destacar que este estudo resulta de pesquisas realizadas entre 2003 e 2006 e está fundamentado, sobretudo, em informações obtidas junto a uma empresa de call center, através da aplicação de 35 questionários aos seus empregados. Ademais, baseou-se também, em informações obtidas através da realização de quinze entrevistas semi-dirigidas, realizadas com gerentes de recursos humanos e trabalhadores.

A empresa investigada permitiu entrevistas semidirigidas, mas não a aplicação de questionários. Os questionários foram aplicados diretamente aos empregados,

Segundo dados da Associação Brasileira de Telemarketing (ABT), as empresas de call centers empregavam, ao final de 2006, aproximadamente 675 mil trabalhadores no Brasil. Os dados do Ministério do Trabalho e Emprego indicam que eram 241 mil empregos formais, em 2005, com crescimento superior a $90 \%$ em relação a 2003 , quando foram contabilizados 125 mil empregos. A significativa diferença no número de empregos, revelada entre os dados das organizações especializadas, em contraste com os dados oficiais, aponta para o momento singular de expansão do segmento de call centers e das atividades de operadores de telemarketing no Brasil. Tal fato caracterizaria a situação de uma atividade laboral em franco crescimento. Além disso, deve-se considerar que haveria, nessa atividade, uma leva considerável de trabalhadores autônomos. Se não há consenso quanto ao número de empregos criados na atividade de telemarketing, muitos menos há em termos qualitativos, o que impede generalizações como as propostas por alguns estudos.

No Brasil, apesar de os call centers terem sido objeto de pesquisas acadêmicas nos últimos anos, ainda se necessita de investigações que com- de forma aleatória, quando eles se deslocavam da empresa, uma vez que não havia a autorização para a aplicação no seu interior. Deve-se ressaltar, entretanto, que essa dificuldade permitiu a aplicação dos questionários sem intermediação, ou seja, num contato direto com os trabalhadores e fora do ambiente da empresa. Destaca-se, contudo, que os dados obtidos, quando contrastados com as informações sobre a ocupação de operadores de telemarketing do banco de dados da Rais-Caged, que engloba o universo do emprego formal nessa atividade, apresentam importantes aproximações.

No período do estudo, o call center investigado era o líder desse mercado no Brasil, com $20 \%$ dos empregados. Convém destacar também que esse call center é de propriedade de um grupo multinacional de telefonia, atuante no Brasil desde 1999. A controladora do call center atua em 13 países, consolidando-se como uma das maiores companhias de telecomunicações do mundo e está entre as primeiras na América Latina. Segundo a revista Infoexame (2002, n.197, p.76-77), o call center investigado estaria entre as maiores empresas de outsourcing (serviços operacionais) do Bradas atividades de telemarketing e cerca de $10 \%$ 
sil, com receita operacional bruta de US\$ $256 \mathrm{mi}-$ lhões, em 2001, 26 mil empregados, cerca de dois mil no Rio Grande do Sul, com crescimento da receita operacional chegando a 77,3\%, entre 2000 e 2001.

O campo de atuação do call center investigado não se restringe exclusivamente a empresas de telecomunicações, pois seu trabalho envolve diversos segmentos: no Brasil, eram 140 clientes de segmentos como governo, bancos, mídia, provedores, telecomunicações, companhia aérea, e outros de menor porte.

No Rio Grande do Sul, o call center atende a cinco clientes, sendo que 90\% do seu quadro pessoal está direcionado para o atendimento de uma empresa de telefonia celular e um provedor de acesso à Internet. Esses são os dois maiores contingentes da mão-de-obra do call center, e algumas distinções entre os dois segmentos serão apontadas no decorrer do estudo. Ressalta-se ainda que a empresa investigada realiza telemarketing ativo e receptivo e opera em sede própria, exceto no caso de um cliente do setor financeiro, que fornece a estrutura física para a realização das atividades.

\section{CALL CENTERS E TELEMARKETING: novas atividades laborais}

Os call centers movimentaram grande volume de recursos financeiros nos últimos anos. Em 2000, os call centers movimentaram, apenas no mercado brasileiro, US\$ 521 milhões, segundo o levantamento do instituto de pesquisas International Data Corporation (IDC). Na fase inicial de implementação dessas empresas no país, o faturamento dos call centers, segundo o estudo "Brazil Call Center Services, 2001", representa apenas 3,1\% do total movimentado pelo segmento nos Estados Unidos e 1,7\% do mercado mundial; em relação à América Latina, o percentual sobe para 55,7\%.

Realizada pela Larc Pesquisa de Mercado e divulgada pela ABT, a " 6 a Pesquisa Anual de Telemarketing" mostrou que a atividade de call center continuava sendo a maior geradora de em- pregos no setor de serviços. Além disso, apresentou números expressivos no que se refere ao faturamento do setor, que foi de US\$ 1,2 bilhão, em 2001. Contudo, o dado mais importante seria o volume estimado de transações apoiadas por serviços de telemarketing, que chegou a R\$ 67,4 bilhões, o que representa uma participação de 6,3\% do PIB brasileiro, naquele ano.

O crescimento expressivo do mercado de call centers tem merecido destacado interesse do meio acadêmico no Brasil e no exterior. No âmbito das discussões sobre as transformações no trabalho e no emprego, frente às mudanças conduzidas pelas tecnologias de comunicação e informação, observam-se duas categorias de serviços: tanto aqueles potencializados pelas tecnologias da informação como os serviços possibilitados por elas. Na primeira categoria, incluem-se, especialmente, aqueles de produção de software, marketing e design, nos quais se executa um trabalho dito "inteligente", que exige dos trabalhadores grande qualificação e escolarização formal de alto grau, com elevado grau de autonomia na execução do trabalho e valorização no mercado de trabalho.

Os call centers estariam entre as atividades que caracterizam a categoria de serviços possibilitados pelas novas tecnologias, com um trabalho "menos inteligente", pouco valorizado no mercado de trabalho, heterônomo e com pouco grau de autonomia na execução do trabalho, mas que necessitam de certo nível de qualificação e escolarização formal, sobretudo ensino médio, habilidades comunicacionais e capacidade de usar o computador.

$\mathrm{Na}$ atualidade, o mercado de call centers tem sido objeto de estudos realizados no âmbito da Sociologia do Trabalho. Entretanto, se os primeiros estudos realizados relacionavam-se a uma abordagem generalista do trabalho nos call centers, destacando, sobretudo, a repetitividade do trabalho e o excesso de controle dos trabalhadores (Del Bono, 2000; Venco, 1999; Oliveira, 2004; Braga, 2006, 2007; Rosenfield, 2007a, 2007b), seria possível afirmar que, na atualidade, outros aspectos são considerados para a compreensão das situa- 
Daniel Gustavo Mocelin,

Luís Fernando Santos Corrêa da Silva

ções concretas de trabalho, tais como: a posição que ocuparia o call center nos processos da empresa, a importância econômica do telemarketing para a empresa que utiliza esse serviço, a natureza das operações desenvolvidas, se relacionadas ao telemarketing ativo ou receptivo, o segmento de mercado atendido, o tamanho da empresa, a complexidade e o ciclo de trabalho. Tais aspectos, incorporados ao debate acadêmico, possibilitaram o surgimento de uma abordagem relacional do trabalho realizado nessas empresas (Kerst; Holtgrewe, 2001; Taylor et al., 2002; Glucksmann, 2004).

A abordagem relacional, apesar de difundida internacionalmente, tem sido preterida, no Brasil, em detrimento de análises ancoradas na abordagem generalista. Nesse sentido, destacamse os estudos realizados por investigadores como Venco (1999), Oliveira (2004) e Braga (2006, 2007).

Um dos estudos pioneiros no Brasil sobre as relações de trabalho nas empresas de call center foi desenvolvido por Venco no final da década de 1990. Em seu estudo sobre a realidade de um call center ligado a uma instituição financeira, a autora afirma que, nele, a organização do trabalho caracterizar-se-ia por princípios tayloristas. Fatores presentes nas atividades de teleatendimento, como a divisão entre execução e concepção do processo de trabalho, controle dos tempos e movimentos no ciclo de trabalho e a seleção científica dos trabalhadores garantiriam a implementação dos métodos tayloristas nas empresas de call center. $\mathrm{O}$ emprego do taylorismo, para Venco, seria viabilizado pelo alto grau de informatização presente nos call centers, o que possibilita o aumento da produtividade do trabalho e o controle eletrônico das atividades: os sistemas de software seriam como ferramentas essenciais na conformação da organização do trabalho (Venco, 1999, p.63). Nessa perspectiva, as novas tecnologias informacionais seriam analisadas sob o ponto de vista determinista de que as tecnologias contribuiriam para a inevitável degradação do trabalho no âmbito do capitalismo.

Passados cinco anos da publicação do estudo pioneiro de Venco (1999), resultados semelhan- tes foram encontrados por Oliveira (2004) ao estudar as relações de trabalho na cadeia produtiva da telefonia fixa do estado de São Paulo, mais especificamente a Atento Brasil, uma das maiores empresas de call center do país. Segundo a autora, os call centers comportariam relações de trabalho baseadas na busca por uma produtividade precisa, articulada a uma racionalização crescente do trabalho. A autora ressalta que há um grande controle do trabalho realizado, que determina o ritmo, as cadências e os procedimentos, sem deixar espaço para uma possível autonomia dos teleoperadores.

Oliveira sustenta que a qualidade nos serviços prestados e a humanização do trabalho estariam colocadas em segundo plano, visto que a aliança entre a empresa de telefonia fixa e a Atento Brasil teria seguido a "lógica que interessa as grandes empresas" (sic), tendo em vista o aumento das possibilidades de redução de pessoal e de controle de custos através da racionalização extrema (2004, p.271).

Recentemente, Braga $(2006,2007)$ argumenta que os call centers representariam o lado negativo do trabalho informacional. Para o autor, o trabalho nos call centers estaria submetido à "pressão do fluxo informacional", o que, por sua vez, acarretaria rotinização da comunicação e subordinação a um script de atendimento pré-definido.

Sobre o trabalho em call centers, Braga sustenta que:

Em última instância, trata-se de um tipo de trabalho que testemunha como nenhum outro a taylorização do trabalho intelectual e do campo das relaçõ̃es de serviço: uma comunicação instrumental sob a coação do fluxo informacional e prisioneira do script tendente a transformar o teleoperador em um autômato inquieto. (2007, p.364)

Para Braga, o objetivo do emprego do taylorismo nos call centers seria, basicamente, de intensificar o ritmo do trabalho, tendo em vista a redução dos custos operacionais, tornando a comunicação um ato instrumental (Braga, 2007, p.364). Contudo, cabe ressaltar limitações dos estudos realizados por Braga, pois, quando o autor se refere aos dados coletados na pesquisa empírica, não há especificação da natureza das operações realiza- 
das e das atividades que foram investigadas. Nesse sentido, assim como nos estudos de Venco e Oliveira, considera-se que o estudo realizado por Braga considera os call centers como um objeto de investigação homogêneo, desconsiderando possíveis diferenças presentes no interior desse segmento de mercado, ou até no interior de uma mesma empresa.

Por outro lado, autores de outros países, situados no contexto da abordagem relacional, como Kerst e Holtgrewe (2001), enfatizam que a organização do trabalho nos centros de teleatendimento pode assumir variadas formas, $\mathrm{e}$ a aplicabilidade dos princípios tayloristas tem se mostrado limitada (Kerst; Holtgrewe, 2001, p.1-2).

Para os autores, a flexibilidade tem surgido como fundamento principal na conformação das práticas organizacionais dos call centers, podendo ser atingida de duas formas: através da flexibilidade externa ou da flexibilidade interna. Suas diferenças residem no fato de que a flexibilidade externa estaria relacionada ao uso que a empresa faz das condições do mercado de trabalho, enquanto que a flexibilidade interna refere-se ao pleno uso das potencialidades da força de trabalho. Cabe ressaltar que, em determinadas situações, tais formas podem estar presentes em uma mesma empresa (2001, p.5).

Para Kerst e Holtgrewe, o surgimento de novos call centers tem levado os observadores a pressupor níveis mais elevados de flexibilidade externa e trabalho precário no mercado de call centers, na Alemanha. Entretanto, diferentes tipos de call centers têm empregado trabalhadores com características distintas, estabelecidas segundo as especificidades ou necessidades dos clientes atendidos (p.6-16).

O exame dessa literatura leva à conclusão de que as generalizações acerca das formas de organização do trabalho em call centers, como as encontradas nos estudos realizados até o presente momento, no Brasil, tendem a equivocar-se, posto que, em geral, baseiam-se em estudos apenas sobre uma atividade específica, num conjunto amplo de atividades relacionadas ao teleatendimento. Assim, tornam-se necessários estudos que abarquem a heterogeneidade do trabalho realizado nos call centers, levando em consideração os aspectos destacados na abordagem generalista, pois eles possibilitariam alargamento da compreensão das relações de trabalho presentes nesse ramo de atividade.

\section{TELEMARKETNGG: como se trabalha no call center}

\section{A atividade de telemarketing: especificidades, natureza da atividade, recrutamento e condições de emprego}

A atividade de telemarketing se distingue do antigo trabalho de telefonista. Até o final dos anos 1980, o telefonista caracterizava-se predominantemente pelo atendimento massificado, baseado em script memorizado. A partir da década de 1990, o operador passou a executar um atendimento inicial ao cliente, menos complexo. No caso de uma questão mais complexa, a ligação deveria ser encaminhada a outro atendente mais qualificado. Recentemente, seria possível afirmar que a atividade envolve novas competências. Os teleoperadores possuem, ou precisariam possuir, capacidade de solucionar dúvidas do cliente sem transferir esse atendimento para outros setores. O desenvolvimento e a introdução constante de novos produtos e serviços no mercado das telecomunicações, por exemplo, requer que os empregados os conheçam, tendo em vista realizar um atendimento satisfatório, bem como devem estar capacitados a solucionar eventuais dúvidas dos clientes.

Em termos de formação e experiência, a descrição da $\mathrm{CBO}^{4}$ indica que o acesso a essas ocupações requer o ensino médio completo até o ensino superior incompleto, seguidos de cursos básicos de qualificação. A qualidade da voz e da audição são requisitos para o trabalho e, em poucas semanas, o profissional estaria apto ao desempenho pleno das atividades. Como competências pessoais, a

${ }^{4}$ A Classificação Brasileira de Ocupações pode ser consultada através do endereço eletrônico www.mtecbo.gov.br. Nesse site, é possível consultar todas as ocupações definidas na classificação, segundo descrição, características da ocupação, requisitos, entre outros. 
Daniel Gustavo Mocelin,

Luís Fernando Santos Corrêa da Silva

CBO destaca: qualidade vocal, clareza de dicção, capacidade de expressão oral, compreensão oral (saber ouvir), capacidade de compreensão e expressão escrita, de registro de informações com precisão, paciência, autocontrole, poder de persuasão, empatia, agilidade no atendimento e agilidade de digitação. Além disso é preciso ter capacidade de administrar conflitos e de ser objetivo para tomar decisões, visto que, em muitos casos, trabalha-se sob pressão. Como recursos de trabalho, são destacados, nessa descrição: a voz, os acessórios de proteção individual, o computador e periféricos, o telefone fixo e call máster, os aplicativos (software), o headset, o correio eletrônico e a Intranet, um posto de atendimento regulável (mesa ergonômica), com apoio de teclado e mouse-pad, e os manuais.

A definição oficial é bastante precisa em relação ao que se observa na rotina de uma empresa de call center. Contudo, nossa pesquisa permitiu observar que, além das diferenciações entre os tipos de telemarketing executados, também há diferentes condições de emprego vinculadas aos tipos de telemarketing, o que não está de todo claro na definição oficial da CBO.

No call center investigado em Porto Alegre, a atividade desenvolvida pode ser de dois tipos: atendimento receptivo e ativo. Entre os trinta e cinco trabalhadores que responderam ao questionário aplicado, oito eram do telemarketing de tipo ativo e 24, a maior parte dos empregados entrevistados, do telemarketing de tipo receptivo, o que expressa o contingente interno da empresa, em que $80 \%$ dos empregados eram atendentes receptivos. O Quadro 1 relaciona as características de cada uma das duas funções, segundo as atribuições do trabalho e segundo o tipo de produto oferecido.

O operador receptivo recebe a chamada dos clientes, sobretudo na área de reclamações, troca de endereço, recebe solicitações de conserto e fornece informações sobre produtos e serviços. No seu trabalho, opera diretamente com o computador e é basicamente dirigido por um script a ser seguido. Os operadores receptivos não têm metas qualitativas a atingir, mas respondem por índices como qualidade e tempo médio de atendimento - em torno de 200 segundos por chamada. No produto massificado, o operador receptivo fornece respostas limitadas. O trabalho caracteriza-se por cumprir metas quantitativas, com tempo de atendimento baixo. No produto customizado, o trabalho do teleatendente receptivo é mais complexo, pois envolve uma demanda de serviços de suporte ao cliente. O tempo de atendimento é menos restrito.

Por outro lado, o operador ativo tem a iniciativa do contato com o cliente, realizando a chamada. Em relação ao operador receptivo, a preocupação do operador ativo com ritmos de velocidade de atendimento é menor, pois ele deve cumprir metas qualitativas, voltadas para a área de vendas e de fidelização. Existem campanhas de vendas e campanhas motivacionais. No produto massificado, o teleoperador ativo tem como tarefa a tele-venda, com autonomia para oferecer o produto. O tempo de atendimento é médio. No produto customizado, o operador tem metas de venda e deve conhecer as características do produto, com autonomia para negociar com o cliente. O tempo de atendimento é flexível, podendo ser longo.

A atividade de telemarketing exige trabalhadores com algumas competências bem desenvolvidas. Contudo, as condições de emprego, especialmente os aspectos relativos à remuneração e à intensidade do trabalho, não podem ser consideradas condições retributivas ou recompensadoras para os trabalhadores. Ficou claro, na entrevista com os gerentes de recursos humanos, que a exigência desse perfil de trabalhador trouxe algumas dificuldades quando da abertura da empresa: "No início, houve dificuldades de recrutamento em função da carência de profissionais treinados para a atividade" (Gerente de RH, entrevista, fev., 2003). A escassez de trabalhadores conduziu as empresas de call center a oferecer o treinamento específico para a atividade de tele-operador, especialmente para o uso do computador. Contudo, os candidatos ao emprego têm chegado com as habilidades computacionais, e os treinamentos passaram a ser realizados mais para a obtenção de informações sobre novos produtos e para desenvolver estratégias de diálogo com o cliente: 
Quadro 1 - Características segundo o tipo de telemarketing

\begin{tabular}{|c|c|c|}
\hline & Ativo & Receptivo \\
\hline $\begin{array}{l}\text { Atribuições da } \\
\text { atividade }\end{array}$ & $\begin{array}{l}\text { Vendas de produtos e serviços } \\
\text { Agendamento de visitas } \\
\text { Fidelização e satisfação de clientes } \\
\text { Pesquisas de opinião } \\
\text { Validação e atualização de cadastros } \\
\text { Qualificação de mailing } \\
\text { Divulgação de produtos, serviços e } \\
\text { eventos } \\
\text { Confirmação de presença em } \\
\text { eventos } \\
\text { Prospecção } \\
\text { Wellcome call (ligação de boas - } \\
\text { vindas) } \\
\text { Anti-Attriction } \\
\text { Ligações de cobrança }\end{array}$ & $\begin{array}{l}\text { Atendimento de campanhas de marketing direto } \\
\text { Atendimento a clientes } \\
\text { Recepção de pedidos de vendas } \\
\text { Suporte de eventos } \\
0800\end{array}$ \\
\hline $\begin{array}{l}\text { Produto } \\
\text { Massificado } \\
\text { (simples) }\end{array}$ & $\begin{array}{l}\text { Tele-vendas/Telemarketing, } \\
\text { sondagens, pesquisa de opinião, } \\
\text { Welcome Calls, prospecção } \\
\text { Objetivo: Quantitativo } \\
\text { Tempo de atendimento médio: } \\
\text { relativa flexibilidade } \\
\text { Suporte Técnico } \\
\text { Média e Baixa complexidade de } \\
\text { serviço } \\
\text { Programação de número de } \\
\text { chamadas } \\
\text { Metas } \\
\text { Baixo salário + comissão }\end{array}$ & $\begin{array}{l}\text { Informações limitadas: campanhas temporárias } \\
\text { Objetivo: quantitativo } \\
\text { Controle permanente do tempo de atendimento: } \\
\text { medição de tempo, rapidez } \\
\text { Script freqüente: soft e hard control } \\
\text { Menor qualificação: treinamento reduzido (1-2 } \\
\text { semanas) } \\
\text { Taylorização } \\
\text { Flutuações de atendimento } \\
\text { Distribuição automática de chamadas } \\
\text { Ausência de autonomia } \\
\text { Baixo salário }\end{array}$ \\
\hline $\begin{array}{l}\text { Produto } \\
\text { Customizado } \\
\text { (complexo) }\end{array}$ & $\begin{array}{l}\text { Objetivo: qualitativo; fidelização, } \\
\text { satisfação do cliente; vendas } \\
\text { Qualificação: capacidade de } \\
\text { negociação; língua estrangeira } \\
\text { Maior autonomia } \\
\text { Metas de vendas } \\
\text { Complexidade média ou forte } \\
\text { Programação de número de } \\
\text { chamadas } \\
\text { Tempo mais elástico; mais flexível } \\
\text { Pagamento "alto" + comissão. }\end{array}$ & $\begin{array}{l}\text { Demanda diversificada, Help desk, suporte técnico } \\
\text { informático, multi-funcional } \\
\text { Objetivo: quantitativo } \\
\text { Qualificação técnica: treinamento longo (4-6 semanas) } \\
\text { Tempo de atendimento médio } \\
\text { Maior autonomia na formulação de respostas } \\
\text { Complexidade média ou alta } \\
\text { Menor controle } \\
\text { Pagamento "mais alto". }\end{array}$ \\
\hline
\end{tabular}

Os funcionários precisam ser pessoas de discernimento muito rápido, de autogerenciamento. Não há necessidade de as pessoas terem capacitação em telecomunicações ou engenharia. Mas não podemos descartar que a tecnologia fica cada vez mais complicada, mas nunca precisaremos ter um funcionário programador. Então, eu não entendo as pessoas que vão ser teleoperadores precisando de uma capacitação específica. Eu quero pessoas que tenham capacidade de relacionamento, capacidade de venda (Gerente de RH, jan., 2005).

Esse trecho de entrevista destaca a preocupação da empresa em desenvolver capacidades que permitam ao operador negociar e argumentar com 
Daniel Gustavo Mocelin,

Luís Fernando Santos Corrêa da Silva

o cliente. A tendência seria a de fornecer "autonomia relativa” para o operador, para que ele seja capaz de, numa estratégia de fidelização e retenção de clientes, convencer através de argumentos, ouvir, diagnosticar, decidir pela situação mais adequada. Dessa forma, o operador seria visto como uma espécie de "assessor" do cliente.

A contratação de pessoal requer exigências consideradas básicas pelos gerentes de recursos humanos. Há duas ordens de exigências: a de cunho formal e a de cunho pessoal. No aspecto formal, é indispensável o ensino médio concluído. Quanto ao aspecto pessoal, destacaram-se as capacidades boa diç̧ão, objetividade, raciocínio rápido e conhecimentos de informática. O treinamento inicial ocorre quando da contração e é realizado num período de 20 a 30 dias, no qual se destacam os cursos de apresentação de produtos, manuseio dos equipamentos e correção da dicção.

Entretanto, além desse treinamento inicial, há treinamentos periódicos para a reciclagem com o produto e (ou) serviço, além de reciclagem com o próprio equipamento. Além desses aspectos, o empregado também precisa responder às exigências do cliente da operadora para quem vai trabalhar.

A forma de organização do trabalho ficaria, portanto, a cargo da gerência do call center. A empresa-cliente da operadora apenas contrata o serviço de telemarketing, deixando toda a administração do trabalho e contratação a cargo do call center. Em alguns casos, a supervisão será contratada da empresa-cliente. Os teleoperadores são contratados pelo call center com exclusividade para uma determinado empresa-cliente, e a qualificação do empregado também depende das exigências dessa empresa:

Quando uma empresa contrata os nossos serviços, nós, já no princípio, na seleção, traçamos o perfil daquele funcionário que vai trabalhar para aquele cliente e para os diferentes segmentos. Nas tratativas com o cliente, é estabelecido o perfil, se vai ser ativo ou receptivo (Gerente de RH, nov., 2003).

É importante considerar que o trabalho numa operadora de call center é diversificado. Existem tele-operadores para atendimento e oferta dos tipos de serviços e produtos, cada um desenvolvendo diferenciadas atividades: atendente receptivo, ativo, generalista (fornece informações no Serviço de Atendimento ao Cliente) e especialista; atendimento para telefonia fixa (mais simples, trabalha apenas com uma tela); ou celular (necessário navegar nas telas, saber os planos em que o cliente está cadastrado e oferecer novos planos de acordo com o valor da conta). Cada uma dessas atividades apresenta um tipo maior ou menor de dificuldade.

As atividades de atendimento, mesmo diversificadas, seguem uma organização-padrão, segundo a forma de gestão adotada pelo call center. Cada grupo de 20 operadores tem um supervisor, que os avalia mensalmente, em termos de desempenho. Há uma proposta de plano de carreira, mas a possibilidade de ascensão profissional é pequena: de operador apenas para supervisor e raramente coordenador ou gerente.

A atividade se define com determinada rigidez. Segundo os gerentes de recursos humanos, não há número fixo de atendimento, mas uma avaliação segundo "as curvas de atendimento". Isso foi possível constatar no questionamento aos empregados, pois as respostas deles indicaram grande variação, de 20 a 150 atendimentos diários. Segundo os resultados obtidos nos 35 questionários aplicados, o número médio de atendimentos realizados por cada teleoperador ficou em 53 por dia. Os gerentes não escondem que a atividade é estressante, mas ressalvam que a empresa procura resolver tais problemas "da melhor forma possível”. O "desgaste emocional” seria compensado com campanhas motivacionais: comemoração de datas, eventos, "brincadeiras", "sorteios", mas essas não são formas que agradam os empregados, servindo, em alguns casos, para aliviar a tensão, mas que também podem criar situações de constrangimento.

A atividade desenvolvida pelos empregados do call center aponta para um novo perfil sócio-ocupacional, principalmente em função de ser essa uma ocupação muito recente, que há poucos anos não existia. Mas os empregados gostam do 
que fazem? Nos 35 questionários, solicitou-se que os empregados atribuíssem uma nota, em escala de zero a dez, para a empresa em que trabalham. $\mathrm{O}$ resultado foi uma média final de 7,1. Uma pergunta também foi elaborada em relação à atividade desenvolvida pelos empregados: solicitados a atribuir uma nota para sua satisfação com o emprego no call center, a média foi 7,2.

Solicitou-se também aos empregados que relacionassem os aspectos que consideram bons e ruins em seu trabalho. O Quadro 2 permite observar os pontos positivos e os negativos apontados pelos 35 entrevistados. Dentre os pontos positivos, destacam-se o pagamento em dia, o cumprimento das leis trabalhistas, a jornada de trabalho mais curta, entre outros. Entre os pontos negativos, os entrevistados destacaram o banco de horas, o trabalho repetitivo, a falta de identificação com a empresa, entre outros.

Um estudo de Bibby (2000), realizado com empregados de call center na Grã-Bretanha, apresenta resultados semelhantes aos encontrados no Quadro 2. Os aspectos negativos registrados pelos dois levantamentos referem-se a: trabalho monótono, passar o dia todo ao telefone, trabalho repetitivo (apontado por 37\% dos entrevistados na pesquisa de Bibby), monitoramento e supervisão (34,6\%), pressão, estresse, sobrecarga, velocidade do trabalho (16,3\%), pausas reduzidas $(11,7 \%)$, poucas oportunidades de crescimento $(10,8 \%)$ e os pagamentos e salários (6,0\%).

Em relação às condições de trabalho, seria importante destacar a falta de identidade dos empregados com o call center, em razão do fato de a empresa prestar serviços para outras empresas. Essa condição faz com que os empregados confundam o

Quadro 2 - Pontos positivos e negativos do trabalho, apontados pelos funcionários da operadora de call center, segundo indicadores selecionados

\begin{tabular}{|c|c|c|}
\hline & Pontos positivos & Pontos negativos \\
\hline Remuneração & $\begin{array}{l}\text { Salário compatível com atividade (20) } \\
\text { Pagamento pontual (25) } \\
\text { Cumprimento de leis trabalhistas (30) } \\
\text { Plano de saúde (10) }\end{array}$ & $\begin{array}{l}\text { Salário Baixo (15) } \\
\text { Baixo valor do cartão lanche (15) } \\
\text { Não tem comissão (exceção vendas) (10) } \\
\text { Banco de horas (20) }\end{array}$ \\
\hline $\begin{array}{l}\text { Condições de } \\
\text { Trabalho }\end{array}$ & $\begin{array}{l}\text { Jornada curta/compatível com estudo ou outra } \\
\text { atividade profissional (22) } \\
\text { Contato com clientes/relações pessoais (15) } \\
\text { Possibilidade de ascensão (6) } \\
\text { Ambiente agradável (15) } \\
\text { Equipamentos atualizados (10) }\end{array}$ & $\begin{array}{l}\text { Metas (15) } \\
\text { Monitoria (16) } \\
\text { Intervalo curto (15 min + } 5 \text { min) (14) } \\
\text { Trabalho mecânico e repetitivo (16) } \\
\text { Folgas durante a semana e trabalho sábados, } \\
\text { domingos e feriados (12) } \\
\text { Trocas de horário (10) } \\
\text { Lanche pouco saudável (15) } \\
\text { Contato entre colegas limitado (10) } \\
\text { Stress (5) } \\
\text { Trabalho no final de semana (12) } \\
\text { Falta de identidade com a empresa (22) } \\
\text { Velocidade do trabalho (11) }\end{array}$ \\
\hline Ergonomia & & $\begin{array}{l}\text { Posição ruim (12) } \\
\text { Hand set (6) } \\
\text { Muito tempo sentado (7) } \\
\text { Não tem ginástica laboral (7) }\end{array}$ \\
\hline Capacitação & $\begin{array}{l}\text { Cursos (10) } \\
\text { Reciclagem com o produto (12) }\end{array}$ & \\
\hline
\end{tabular}


Daniel Gustavo Mocelin,

Luís Fernando Santos Corrêa da Silva

seu real empregador, produzindo a chamada "desterritorialização". Essa concepção é muito discutida nos call centers e em suas associações. A “desterritorialização" consistiria na dificuldade que os empregados de uma empresa terceirizada experimentam, uma vez que são contratados por uma empresa, mas trabalham para outra. Seria difícil para o empregado criar uma identidade com a operadora, uma vez que oscilam entre o empregador-que é a operadora - e o cliente da operadora - para quem o empregado da operadora presta o serviço de telemarketing. Entre os empregados entrevistados, 11 (um terço) deles afirmaram que se identificam com ambas as empresas, tanto com o empregador como com o cliente; apenas dois afirmaram que se identificam com o empregador, que é o call center, e a grande maioria (22 dos 35 entrevistados) identifica-se apenas com o cliente da operadora.

\section{CONDIÇÕES DE EMPREGO DOS OPERADO- RES DE TELEMARKETINGNO BRASIL}

No mercado de trabalho dos operadores de telemarketing, observa-se um baixo grau de remu-

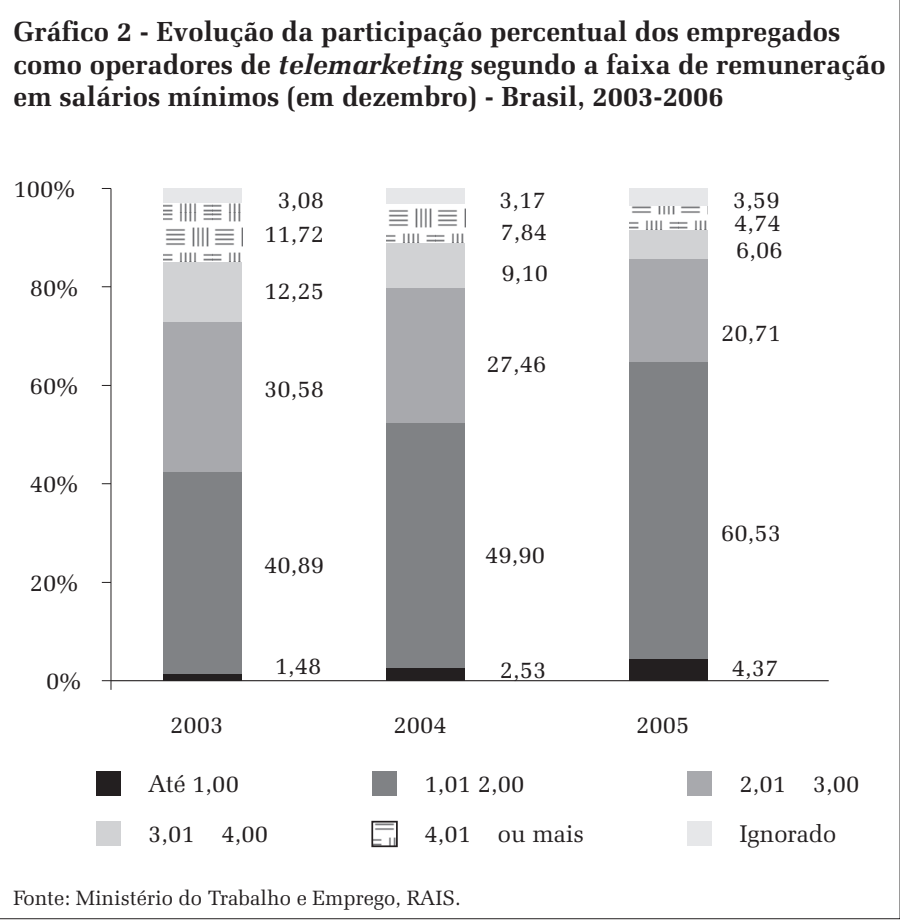

neração. No período analisado, a partir dos dados da Rais, observa-se que, em 2005, mais de $80 \%$ dos empregados recebiam remuneração de até três salários mínimos, como operadores de telemarketing, sendo que mais de $60 \%$ dos empregados recebiam até dois salários mínimos. Entre 2003 e 2005, observa-se um crescimento das faixas de menor remuneração nessa atividade laboral. Os dados analisados permitem constatar que a remuneração desses trabalhadores está aquém das exigências para a inserção nas atividades de telemarketing.

No que se refere ao tempo de emprego, no período de 2003 a 2005 , observa-se que $80 \%$ dos operadores de telemarketing não possuíam mais do que dois anos de emprego. Mesmo se considerando que há significativa geração de postos de trabalho entre os três anos, esse índice de empregados com até dois anos não sofreu modificação significativa; ao contrário, houve redução da participação dos empregados com mais de dois anos de emprego, o que indica uma tendência à não-permanência dos trabalhadores no mesmo emprego.

Os vínculos de emprego dos operadores de telemarketing, ao contrário do que poderia parecer, devido aos dados disponíveis, não se caracterizam por contratos por tempo determinado ou temporários. Nos três anos analisados, os contratos celetistas por tempo indeterminado estiveram na casa de $96 \%$, com redução do número de temporários, que caiu de $3,1 \%$, em 2003, para 1,8\%, em 2005. Essa situação indica que o caráter de emprego temporário assumido para a ocupação de operador de telemarketing não provém da condição contratual, mas do índice elevado de desligamento por iniciativa dos empregados ou de demissões. 
Gráfico 3 - Evolução da participação percentual dos empregados como operadores de telemarketing segundo o tempo de emprego (em meses) - Brasil, 2003-2006

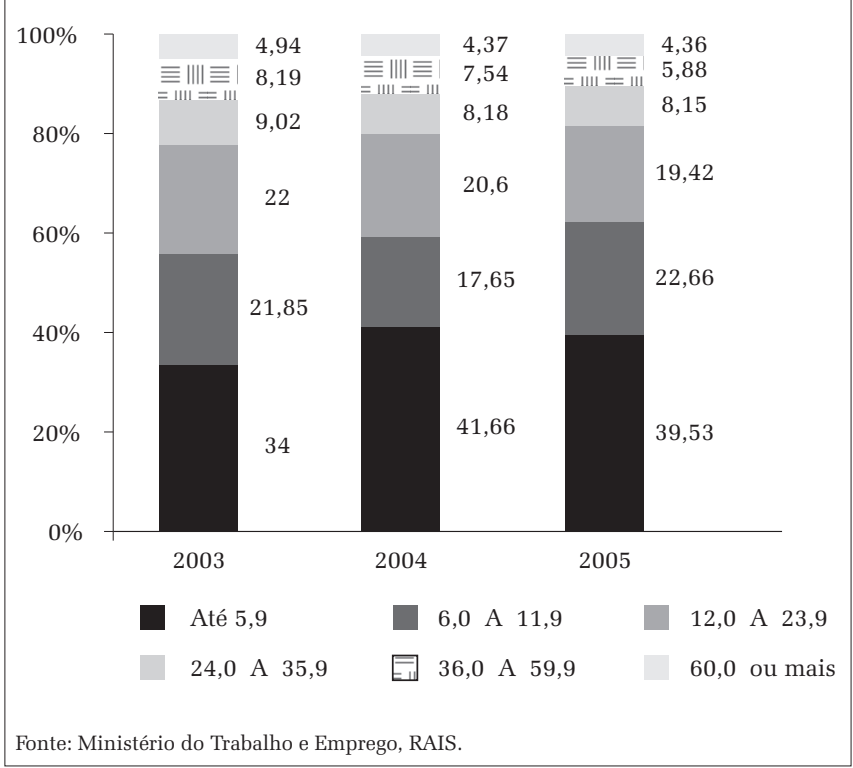

QUEM TRABALHA NO CALL CENTER

O perfil sócio-ocupacional dos operadores de telemarketing no Brasil

Os dados da Rais também permitem fazer importantes inferências sobre o perfil dos opera-

Gráfico 4 - Evolução da participação percentual dos empregados como operadores de telemarketing segundo o sexo

Brasil, 2003-2006

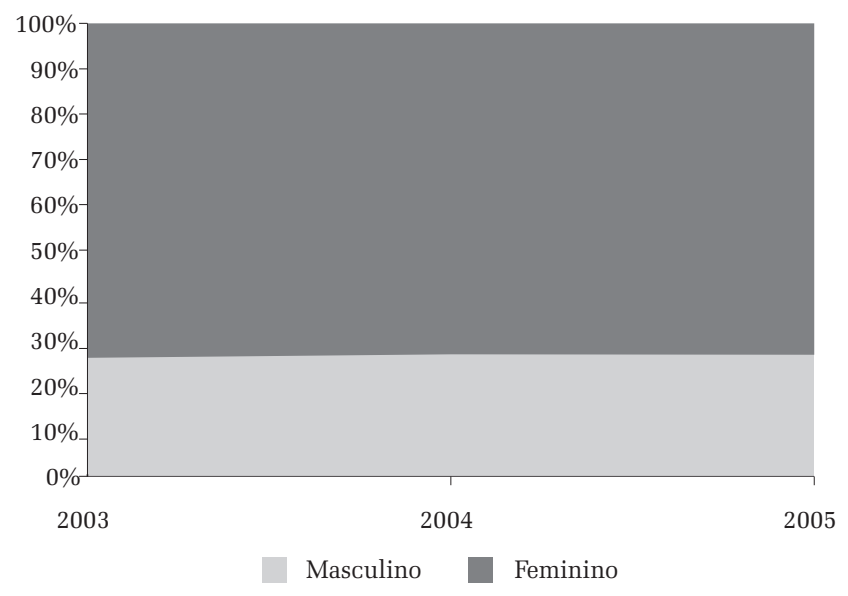

Fonte: Ministério do Trabalho e Emprego, RAIS. dores de telemarketing no Brasil. Observouse que mais de $70 \%$ dos empregados nessa atividade são do sexo feminino, tendência que não sofre modificação no período.

O que também chama atenção é a grande participação de empregados com ensino médio completo, de 70\%, em 2005, percentual que representa o dobro da média do mercado de trabalho brasileiro no seu conjunto, cujo percentual foi de $35 \%$ de trabalhadores com ensino médio. Além disso, há uma grande participação de empregados com ensino superior incompleto, o que indica que, em grande parte, eles são trabalhadores que estão cursando o nível superior. Em 2004, a taxa de trabalhadores com ensino superior incompleto no mercado de trabalho do Brasil é de 4\%, enquanto que, nas atividades de telemarketing, essa taxa é de $20 \%$.

Outro aspecto que se destaca no perfil dos operadores de telemarketing, que condiz com as evidências antes expostas, refere-se à idade dos empregados. Entre 2003 e 2005, ocorre o crescimento da participação de empregados na faixa entre 18 e 24 anos, que passa de $46 \%$ para $52 \%$. Em conseqüência, há uma redução constante nas duas faixas seguintes de idade, ou seja, nas faixas de 25 a 29 anos e de 30 a 39 anos.

Tais dados evidenciam que haveria uma constante inserção de trabalhadores mais jovens nas atividades de telemarketing, o que implica não haver envelhecimento dos empregados, sobretudo devido à elevada rotatividade da mão-de-obra. A partir de 25 anos de idade, ocorre uma redução da participação de empregados nas faixas de idade que vão de 25 a 29 anos e de 30 a 39 anos. Isso indica uma tendência de esses empregados saírem do emprego quando atingem uma determina faixa de idade, o que parece coincidir com o crescimento da formação. 
Gráfico 5 - Evolução da participação percentual dos empregados como operadores de telemarketing segundo a escolaridade Brasil, 2003-2006

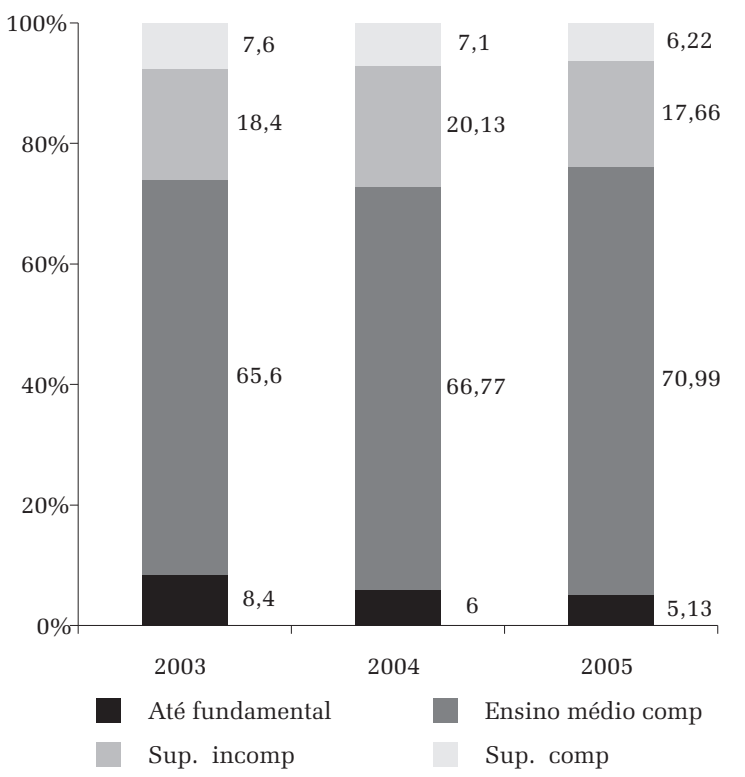

Fonte: Ministério do Trabalho e Emprego, RAIS.
Lembremos que o call center investigado trabalha com dois grandes clientes: uma operadora de telefonia móvel e um provedor de Internet. Notelemarketing dos serviços de telefonia móvel, é mais abrangente o número de mulheres, enquanto, no trabalho com oprovedor de Internet, estão mais presentes os homens, embora, em termos de qualificação formal (escolarização), nenhum dos segmentos seja mais adequando a um ou a outro gênero.

A maior parte dos empregados são pessoas bastante jovens: dos 35 entrevistados, 29 têm até 29 anos. Não há trabalhadores com idade inferior a 18 anos, pois essa seria a idade mínima para a contratação. O Gráfico 7 mostra que 17 entrevistados têm entre 18 e23 anos, seguidos de 12 que estão na faixa entre $24 \mathrm{e}$ 29 anos, enquanto que apenas 6 têm mais de 30 anos. Segundo entrevista realizada com a coordenadora do call center, a em-

O PERFILSÓCIO-OCUPACIONALDOS OPE- possuiriam mais facilidade para lidar com as freRADORES DE TELEMARKETING NO CALL CENTER INVESTIGADO

As evidências sobre o perfil sócio-ocupacional dos operadores de telemarketing, constatadas para o caso do Brasil, confirmam-se também para o caso analisado em Porto Alegre, apesar da pequena amostra. Considerando-se o conjunto dos empregados, as entrevistas realizadas mostram que as mulheres são a maioria dos trabalhadores, pois representaram 25 dos 35 indivíduos que responderam ao questionário. No caso do call center investigado, a divisão sexual do trabalho apresenta peculiaridades que não são facilmente constatadas pelos dados gerais para o Brasil, embora as tendências gerais entre as duas bases de dados (Rais e pesquisa direta) coincidam.

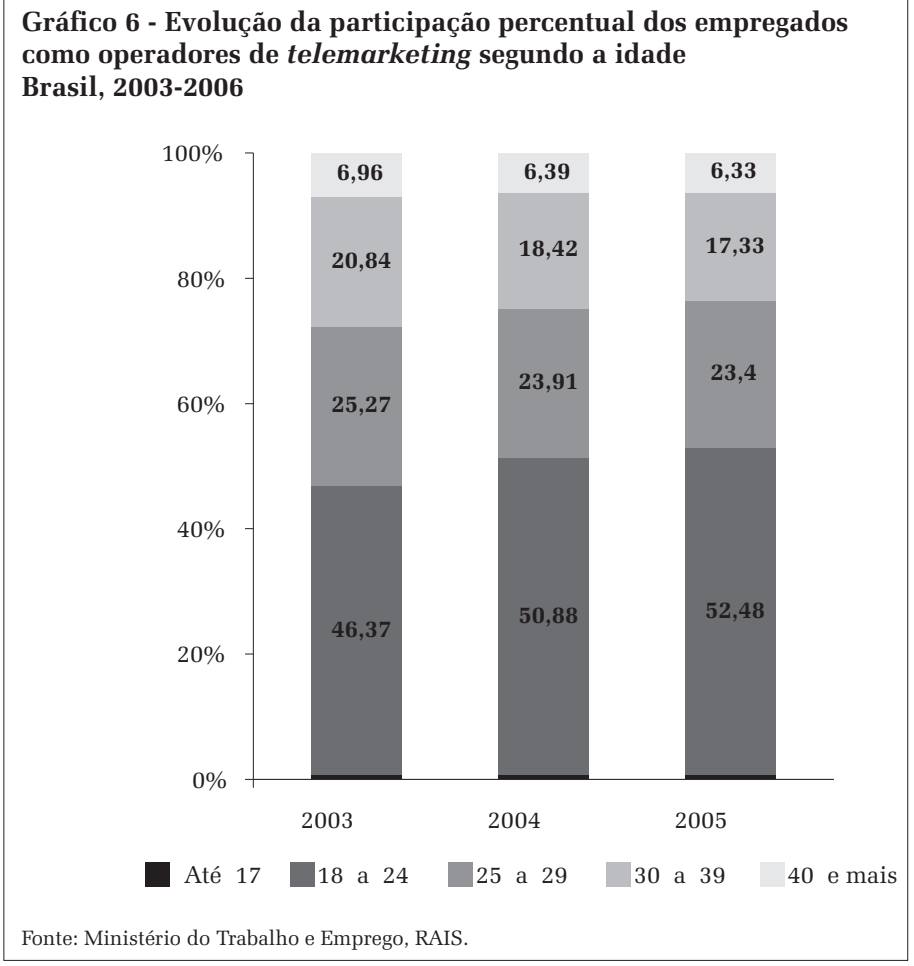

Gráfico 6 - Evolução da participação percentual dos empregados como operadores de telemarketing segundo a idade 
qüentes transformações na base operacional e tecnológica, principalmente as relacionadas à informática e à Internet. Mas isso também está vinculado à perspectiva de que os empregados mais jovens, quando adquirem outra formação, deixam os empregos na atividade de telemarketing, fato evidenciado pela pequena incidência ou ocorrência de empregados com maior faixa etária.

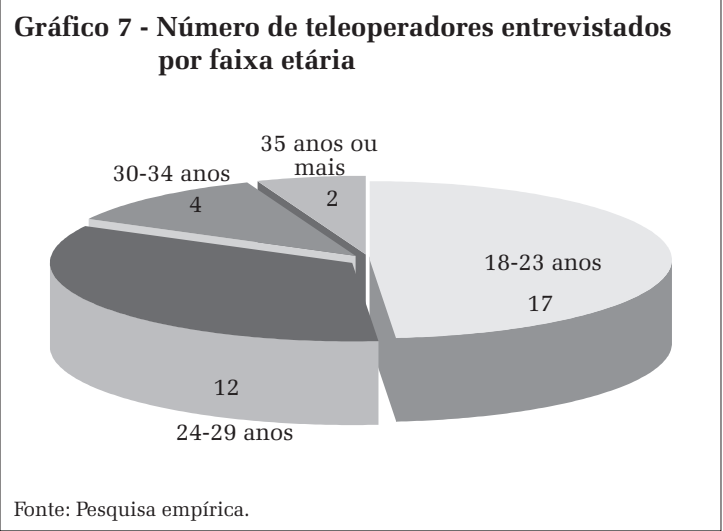

No que se refere à escolaridade, a exigência mínima é de ensino médio completo para os teleoperadores, mas há estímulo para que o atendente prossiga os estudos, uma vez que lhes são “prometidas" oportunidades de ascensão profissional. Muitos dos funcionários vêem seus colegas ascenderem à função de supervisores, pois, segundo a política da empresa, ter sido um "bom" atendente é condição para ser supervisor. No call center estudado, observou-se que 14 dos empregados entrevistados têm o ensino médio, seguidos de 11 entrevistados com o ensino médio técnico.

Gráfico 8 - Número de teleoperadores entrevistados por escolaridade

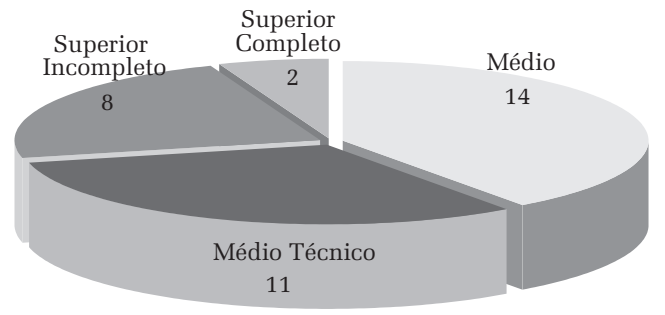

Fonte: Pesquisa empírica.
É interessante observar que oito dos operadores empregados estão cursando o ensino superior, o que é facilitado pela carga horária diária de 6 horas. Empregados com ensino superior completo aparecem em parcela reduzida, o que remete à idéia de que os trabalhadores, ao ascenderem em termos de formação, não permanecem na atividade de telemarketing.

A literatura internacional destaca que os call centers empregam muitos trabalhadores em fase inicial de inserção no mercado de trabalho, muitos deles em situação de primeiro emprego. No caso investigado, foi possível confirmar tal observação, embora essa não seja a situação da maior parte dos empregados. No Gráfico 9, verifica-se que, dos 35 operadores que responderam ao questionário, 6 estão ainda em seu primeiro emprego. Entretanto, a posição prevalecente é a de operadores que provieram do setor de comércio (15 dos 35 entrevistados), oriundos de outros empregos, como vendedores de lojas.

Fato já mencionado, a atividade de telemarketing possui características em comum com a de vendedor, no que se refere à facilidade em comunicar-se com as pessoas e de convencer o cliente. Assim, no caso de o atendente ativo ter sido vendedor "presencial", essa experiência pode ser um requisito importante para trabalhar com televendas. A segunda posição entre as atividades anteriores é a do ex-operador, pois oito dos entrevistados dizem ser provenientes da própria atividade, tendo exercido a mesma ocupação em outro call center. Contudo, esse dado não parece sugerir

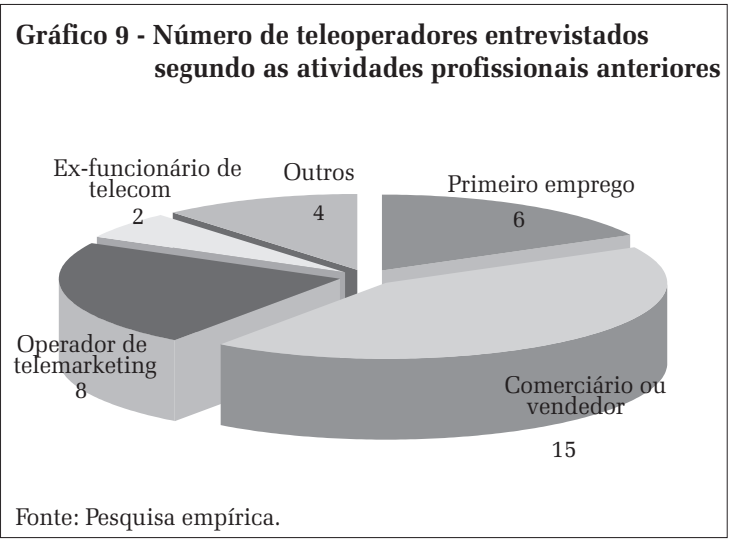


Daniel Gustavo Mocelin,

Luís Fernando Santos Corrêa da Silva

a existência de um processo de profissionalização dessa ocupação, como afirmaram os gerentes de recursos humanos: "a atividade pode ser considerada uma profissão, pois já existe uma rotatividade de trabalhadores entre as empresas que prestam serviços de telemarketing (Entrevista, março de 2003)". Na verdade, essa idéia não coincide com a opinião da maior parte dos trabalhadores, que consideram ser esse um emprego temporário, ou que ele seria mais uma ocupação do que uma profissão. Além disso, a remuneração é baixa para trabalhadores que possuem ensino médio ou superior incompleto, em relação ao mercado de trabalho em geral. Os benefícios extra-salariais são poucos: vale-alimentação e vale-transporte.

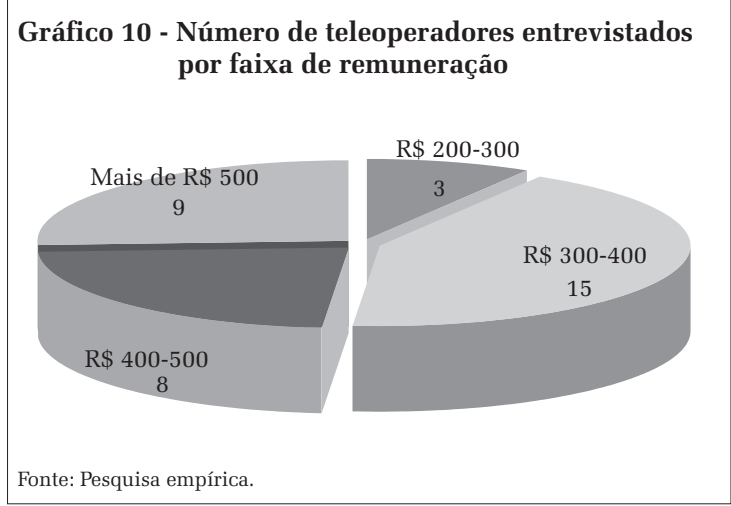

Em 2004, o piso salarial no call center investigado era $\mathrm{R} \$ 350,00$ para jornada de seis horas, mas variava de acordo com funções e a área de atuação, podendo haver ainda ganhos variáveis de produtividade para cargos de venda, de supervisão, ou superiores. A maior parte dos empregados da operadora é constituída de jovens estudantes, muitos que estão ali apenas para obter renda, ou seja, o trabalho de teleoperador seria uma atividade temporária. Muitos deles têm ainda atividades paralelas. Nesse caso, o emprego de teleoperador seria uma forma de aumentar a renda. Sobre a remuneração, destacou um gerente:

Hoje [2004], o salário fixo da nossa categoria, para uma jornada de quatro horas, é de 220 reais. E de 350 reais para seis horas. Esse é o mínimo. Nós contratamos por menos no contrato de experiência, respectivamente 206 e 310 reais. Depois de 90 dias, fica normal. Comissões só exis- tem em serviços de vendas (Gerente de RH, mar., 2004).

No que se refere às questões de gênero, os salários apresentam uma homogeneidade, não havendo diferença segundo o sexo. A estrutura de remuneração dos teleoperadores varia conforme sua função ou segmento de atendimento. Nos dados do Gráfico 10, constata-se que 15 dos 35 trabalhadores que responderam ao questionário recebiam entre 300 e 400 reais, seguidos de nove teleoperadores que recebiam mais de 500 reais; oito entrevistados recebiam entre 400 e 500 reais, e apenas três recebiam entre 200 e 300 reais (nesse caso, empregados em contrato de avaliação, muitos com jornada de 20 horas semanais).

A atividade de telemarketing não se caracteriza por empregados com longo tempo no emprego. Segundo as entrevistas com os empregados, apenas quatro dos 35 entrevistados têm entre 2 e 3 anos de empresa. Outros quatro entrevistados estão há mais de três anos na empresa. Chama a atenção o fato de que 27 dos entrevistados estavam empregados há cerca de um ano e meio, sendo que oito deles há menos de seis meses. Para complementar a idéia de que os empregados em call centers não permanecem muito tempo no emprego, até mesmo por iniciativa própria, podemse acrescentar os dados do Gráfico 12: dos 35 entrevistados, 14 consideram a atividade ocasional e temporária, e oito dizem estar em constante procura por uma melhor oportunidade de trabalho, sem mencionar que três deles dizem estar na atividade

Gráfico 11 - Número de teleoperadores entrevistados por tempo de emprego

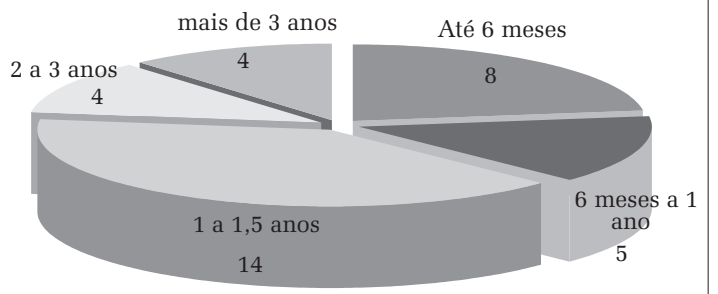

Fonte: Pesquisa empírica. 


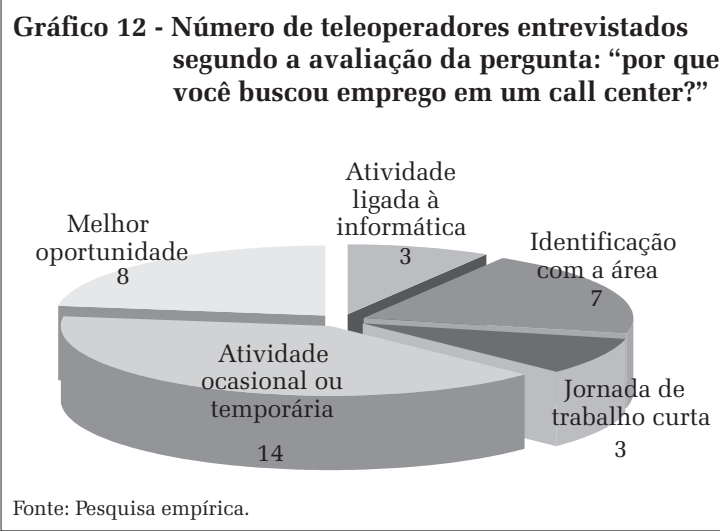

por ela ser, de alguma maneira, relacionada com a informática. Três estão no emprego devido à jornada de trabalho ser curta, o que foi indicado como um ponto positivo desse tipo de emprego.

A perspectiva defendida de que o trabalho em call center seria emprego transitório se reforça quando se observa que apenas sete dos 35 teleoperadores entrevistados dizem buscar emprego no setor por identificação com a área. Esses elementos permitem reforçar a idéia de que não há um processo de profissionalização nesse tipo de emprego, sobretudo porque os próprios trabalhadores, em grande parte, não querem ser profissionais do telemarketing, devido às poucas perspectivas de ascensão profissional. Não se pode dizer, portanto, que as atividades de telemarketing seriam atrativas para o trabalhador. A atividade de telemarketing assumiria esse sentido apenas no que se refere às conveniências particulares dos próprios empregados: atividade ocasional, jornada curta, pagamento pontual, direitos trabalhistas. No que

Gráfico 13 - Número de teleoperadores entrevistados segundos a avaliação das suas perspectivas em seguir carreira no call center

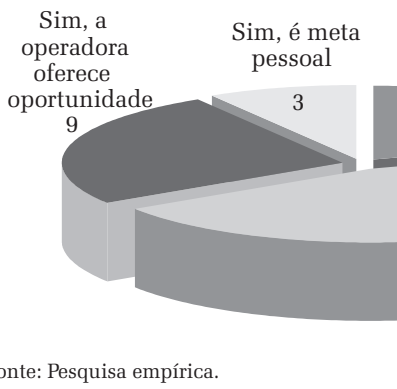

Fonte: Pesquisa empírica. se refere à perspectiva de seguir uma carreira na empresa (Gráfico 13), dos 35 entrevistados, 12 dizem que sim, poderiam seguir carreira; entretanto, 23 dos entrevistados dizem que não: 16 justificam pelo fato de ser um trabalho temporário, e por se tratar de atividade limitada, sem perspectivas futuras.

Alguns outros elementos podem ser combinados entre os dados dos 35 questionários, que dizem respeito ao fato de a atividade de telemarketing caracterizar-se como um emprego-trampolim. A alta rotatividade, associada à idade mais jovem, não permite a existência de empregados com muito tempo de serviço na empresa. Entre os 35 respondentes, observou-se que apenas oito empregados têm mais de dois anos de atividade, sendo que 13 responderam estar empregados há menos de um ano. Além disso, observou-se que 28 empregados não se identificam com a área (Gráfico 12). A rotatividade elevada nos call centers também significaria pensar na rápida recolocação de trabalhadores, ou seja, quanto maior a rotatividade, maior seria a inserção de novos empregados e menor seria o grau de desemprego nessa atividade.

Assim, os dados expostos indicam descontinuidade profissional. No call center, observou-se que 23 dos entrevistados não vêem perspectiva de continuar na empresa, como antes foi destacado, a maior parte deles por considerar a atividade como ocasional ou temporária. Esse é um aspecto que pode estar relacionado a uma tendência de flexibilidade na própria intenção do jovem ao se empregar em atividades vinculadas à informática. É interessante observar que, mesmo quando a pergunta foi diferente (Gráficos 12 e 13), as respostas sobre o emprego ser temporário continuam recorrentes.

Essas condições também reforçam um falso sentido de participação sindical nos empregados nos call centers. Eles respondem a questão sobre "participação no sindicato" restringindo-se ao pagamento do imposto sindical. Entretanto, esse imposto é obrigatório. Os empregados não visualizaram a participação, por exemplo, associada à freqüência às assembléias, para debaterem aspectos relacionados às suas condições de trabalho 
Daniel Gustavo Mocelin,

Luís Fernando Santos Corrêa da Silva

e realizarem reivindicações. De fato, não há grandes perspectivas de mobilização para melhorar as condições de emprego, uma vez que os próprios trabalhadores não se consideram uma categoria profissional. Em muitos casos, houve relatos de que o sonho dos teleoperadores era trabalhar nas empresas-cliente que eles representam a partir do call center. Esse sentimento, somado a todas as outras evidências antes destacadas, nos conduz a pensar a atividade de operadores de telemarketing como uma saída para a desocupação e para a falta de recursos financeiros, ou, ainda, como uma entrada no mercado de trabalho, uma vez que garante ao trabalhador remuneração e direitos trabalhistas, o que lhes permite pagar um curso profissionalizante, seja técnico ou superior.

Mas que características desses empregos seriam atraentes aos jovens? As evidências encontradas em entrevistas e depoimentos indicam:

- Contratação imediata, devido à alta rotatividade e à rápida substituição do empregado.

- Jornada de trabalho flexível e mais curta, apropriada para compatibilizar, por exemplo, educação com emprego, ou até mesmo dois empregos. - Fonte de renda para custear educação técnica ou superior e (ou) satisfazer à necessidade de consumo;

- Qualificação mediana como requisito de contratação, cada vez mais recorrente para os jovens: ensino médio e "saber operar um computador".

- Qualificação pessoal: habilidade de comunicação e compreensão de procedimentos, comuns ao jovem de escolarização média; oportunidade de aprendizado, no sentido de que esse emprego pode ser "mais uma experiência profissional". - O emprego em call center mais como ocupação e menos como profissão: pouca perspectiva de crescimento nas empresas ou nas atividades (da mesma forma que a empresa "usaria" o empregado, o empregado "usaria" a empresa).

· Emprego como “meio”ou passagem para outra situação, que pode ser idealizada pelo jovem.

Tais evidências indicam que os empregos com base em tecnologia de informática se caracterizam como local para inserção de jovens no mer- cado de trabalho, pois são atividades que requerem trabalhadores semi-qualificados, mas sem exigência de experiência profissional, de rápido treinamento, fornecendo remuneração, mesmo que baixa, suficiente para fomentar educação e (ou) satisfazer necessidades imediatas de consumo. Nesse sentido, as atividades em informática parecem potencializar a própria empregabilidade de trabalhadores jovens.

\section{SEGMENTAÇÃO INTERNA INDICAABORDA- GENS MAIS COMPLEXAS}

No call center investigado, a segmentação nos tipos de atendimento acarreta distinções no perfil dos trabalhadores que compõem cada uma das atividades desenvolvidas. Também ocorre distinção no perfil dos empregados do call center segundo o cliente atendido. Além das características básicas do trabalho no call center, os empregados também precisam responder às exigências do cliente para o qual vão trabalhar, pois eles representam com exclusividade a empresa-cliente, de cujas exigências sua qualificação depende. A gerência do call center investigado faz referência ao diferente perfil dos empregados quando se trata do cliente da empresa:

Para trabalhar no atendimento, é necessário o segundo grau completo, ter o conhecimento de informática básica, e, dependendo do cliente, o requisito que o cliente pedir... Porque, por exemplo, um operador do Provedor de Internet não chega só a isso: é preciso um operador mais preparado: que tenha vindo de uma escola técnica, que tenha um conhecimento maior, que tenha que ter um perfil, senão eu vou ter dificuldade de passar, de formar esse funcionário. Há um treinamento de um mês, com 10 ou 12 telas, ele vai ter de pesquisar para encontrar as informações que ele precisa (Gerente de RH, nov., 2003).

Nas tratativas com o cliente, é estabelecido o perfil, se vai ser ativo ou receptivo... Dependendo do serviço para qual eu estou sendo contratada, eu [o call center] preciso buscar o funcionário adequado para aquela atividade. O funcionário é buscado no mercado, e contratado especificamente para aquele cliente. Então, ele é um funcionário para atender àquele cliente, mas é um funcionário do call center. Mas, ele, entre aspas, veste a camiseta do cliente. Então, todo o funcionário que eu tenho hoje, eles foram selecionados, eles têm o perfil que o cliente precisa, e recebendo o treinamento 
do cliente, e, por isso, são exclusivos daquele cliente (Gerente de RH, mar., 2004).

O provedor de Internet tem uma gama diversificada de servicos. Nós somos 1.000 funcionários trabalhando com o site. Tem ativo, tem cobrança, tem relacionamento com o cliente, tem suporte, tem entrega de Kits, tem resposta a email, tipo uma ouvidoria. Para cada segmento do provedor, eu tenho um determinado perfil de funcionário (Gerente de RH, mar., 2004).

Constatou-se que o teleatendimento nos serviços de telefonia móvel é realizado, sobretudo, por mulheres, enquanto para o provedor de Internet seria maior o número de homens, embora nenhum dos setores seja mais adequando a um só gênero. Segundo os gerentes de recursos humanos, no serviço de telefonia móvel predominam mulheres porque o trabalho envolve atendimento que exige relativa "docilidade" na comunicação, comportamento que seria naturalizado como característica intrínseca da condição feminina. No provedor de Internet, o atendimento é mais voltado ao suporte técnico, ou seja, o teleoperador precisa estar preparado para auxiliar o cliente quanto há dúvidas referentes à utilização de tecnologias informacionais, principalmente conexão à rede mundial de computadores e configuração do sistema operacional. Nesse caso, os trabalhadores do sexo masculino são predominantes.

$\mathrm{O}$ treinamento do empregado também se distingue em termos do cliente para o qual trabacelular e os que atendem ao provedor de internet

Fonte: Pesquisa empírica: questionários e entrevistas. diferentes remunerações. Por exemplo, o provedor de Internet requer mais qualificação técnica na área de informática. A atividade do atendente de bancos também é diferente da atividade do atendente de telefonia móvel. O treinamento é mais longo para teleoperadores do provedor (período de tempo que compreende um mês, visto que necessita realizar pesquisa em 10 ou 12 telas) e de bancos (45 dias e, em certos casos, há exigência de conhecimento de línguas estrangeiras). Entretanto, além desse treinamento inicial para assumir a função, existem treinamentos periódicos para a reciclagem com o produto do cliente da operadora, além da reciclagem com o próprio equipamento.

As diferenças na atividade de telemarketing, segundo a empresa-cliente, apontadas no Quadro 3 , não implicam que, com um ou com outro cliente, haja uma situação diferenciada em termos de essa atividade ser um emprego de passagem. Da mesma forma, como já foi apontado anteriormente, o tipo de telemarketing, ativo ou receptivo, não conduziu a uma idéia diferente. Mesmo que haja uma "melhor" condição segundo o tipo de empresa-cliente e segundo o tipo de telemarketing, as condições de emprego, especialmente o salário e as possibilidades de ascensão nas empresas, não são condizentes com o perfil sócio-ocupacional dos trabalhadores, sobretudo no que se refere à qualificação e às competências cognitivas requeridas.

Quadro 3 - Distinções de perfil entre os empregados do call center que atendem à operadora de telefonia móvel

\begin{tabular}{|l|l|l|}
\hline \multirow{2}{*}{ Perfil } & \multicolumn{2}{c|}{ Cliente do call center } \\
\cline { 2 - 3 } & \multicolumn{1}{|c|}{ Operadora de telefonia } & \multicolumn{1}{c|}{ Provedor de Internet } \\
\hline Tipo de atendimento contratado & Ativo e receptivo & Ativo e receptivo \\
\hline Atividades atendidas & $\begin{array}{l}\text { Campanhas, programação de novos } \\
\text { serviços e desativação de serviços, } \\
\text { dúvidas sobre aparelhos, serviços e } \\
\text { contas do usuário; mudança de } \\
\text { planos, reclamações e resolução de } \\
\text { problemas }\end{array}$ & $\begin{array}{l}\text { Suporte técnico, principalmente } \\
\text { instalação e configuração de serviços; } \\
\text { tratamento de contas do usuário, } \\
\text { mudança de planos e ativação de } \\
\text { serviços }\end{array}$ \\
\hline Qualificação & $\begin{array}{l}\text { Ensino médio, capacidade de } \\
\text { comunicação e docilidade. } \\
\text { Conhecimento básico em } \\
\text { informática. Treinamento pelo } \\
\text { cliente para atendimento ao usuário }\end{array}$ & $\begin{array}{l}\text { Ensino médio e técnico em informática. } \\
\text { Conhecimento mais apurado de } \\
\text { conceitos de informática. Treinamento } \\
\text { chegar codimentos do cliente, mas deve } \\
\text { chenhecimentos técnicos }\end{array}$ \\
\hline Sexo & Predomina feminino & Predomina masculino \\
\hline Idade média (faixa predominante) & 20 anos (18-24) & 23 anos (20-25 anos) \\
\hline Remuneração média & R\$ 450 & R\$ 750 \\
\hline
\end{tabular}


Daniel Gustavo Mocelin,

Luís Fernando Santos Corrêa da Silva

As entrevistas qualitativas realizadas com teleoperadores complementam as idéias até aqui apresentadas sobre o emprego em call centers. Constatou-se que os trabalhadores envolvidos neste estudo são atores que conhecem muito, discursiva e tacitamente, a respeito do ambiente social em que vivem, do seu potencial de inserção no mercado de trabalho e das suas reais possibilidades profissionais. As entrevistas realizadas permitiram constatar que os empregados de call centers podem dizer muito acerca de suas opiniões sobre o ambiente empresarial no qual vivem, suas expectativas profissionais, suas estratégias para almejá-las e também sobre o porquê de reagirem do modo como o fazem frente à realidade.

Mais do que se conformarem com a situação que se lhes é "apresenta”, na qual seriam "sujeitados", os trabalhadores demonstraram estar reagindo através de estratégias elaboradas a partir das possibilidades por eles encontradas.

Nesse sentido, talvez seja problemático recorrer a categorias analíticas tradicionais para explicar a situação específica das atividades de telemarketing ou do trabalho em call centers, tais como identidade, filiação sindical ou estabilidade (Venco, 1999; Oliveira, 2004; Braga, 2006, 2007; Rosenfield, 2007b), critérios determinados por alguns estudos para sugerir a precarização do trabalho na atividade de telemarketing. Nosso estudo sugere que tais categorias analíticas são pouco representativas no caso investigado. Em relação à identidade profissional, por exemplo, parece frágil argumentar acerca de uma identidade provisória ou transitória do trabalhador em call centers (Rosenfield, 2007b), pois eles mesmos não almejam essa identidade e buscam tais empregos convencidos disso. No caso da filiação sindical, não há interesse significativo por parte dos empregados em participar de mobilizações por melhorias nas condições de emprego, uma vez que, quanto mais tempo ficam nesses empregos, menos têm perspectivas profissionais na atividade. No caso de estabilidade, os trabalhadores consideram que um emprego desse tipo que fosse "estável" não seria interessante para eles, pois a ocupação de teleoperador limitaria as oportunidades de trabalhadores do perfil sócio-ocupacional arrojado, caso que parece ser recorrente no meio do telemarketing, e, além disso, o trabalho seria mais intenso e repetitivo, bem como limitador.

\section{CONSIDERAÇÕES FINAIS}

A realização do presente estudo sugere que o novo perfil sócio-ocupacional que se desenha para esse segmento do mercado de trabalho estaria relacionado com as transformações no trabalho e no emprego, especialmente no caso da emergência de novas ocupações, em que haveria necessidade de um grau elevado de escolarização, como o ensino médio e o uso de tecnologias de informação e comunicação.

Em relação ao como se trabalha, constatouse que é fundamental ao empregado ser capaz de utilizar adequadamente as tecnologias necessárias para a realização do trabalho. Para lidar com sistemas tecnológicos dessa natureza, o empregado deve possuir certa "qualificação", "ser usuário de computador", bem como possuir conhecimentos em informática e Internet, além de realizar treinamentos de reciclagem com os produtos oferecidos, em sua maior parte produtos da tecnologia. A maior dificuldade é que o empregado precisaria satisfazer também às características pessoais exigidas por esse segmento, ou seja, possuir boa dicção, capacidade de comunicação, cordialidade e capacidade de negociação. Não se pode deixar de supor que um trabalhador com essas competências e portador de escolarização ascendente pretenda profissionalizar-se em atividade que não o retribua adequadamente.

Em relação a quem trabalha, o novo perfil sócio-ocupacional é de empregados entre 18 e 30 anos de idade, acostumados a lidar com tecnologias informacionais. Não há distinção em relação ao sexo no que concerne a salários, por exemplo. Mas deve-se destacar que a maior parte dos operadores de telemarketing são mulheres. A distinção no nível da remuneração ocorre, sobretudo, em relação 
ao tipo de atividade desenvolvida. Por exemplo, os homens que trabalham com o provedor de Internet recebem melhores salários que as mulheres, visto que estão mais presentes nessa ocupação, em que a exigência por qualificação técnica é maior. Convém destacar que o teleoperador provém, em grande parte, do setor de comércio. Os salários são baixos, embora exista certa satisfação para os teleoperadores ativos, pois recebem comissão por vendas realizadas.

Por outro lado, o teleoperador receptivo tem jornadas de trabalho menores, o que também tem sido um atrativo para trabalhadores em início de carreira e que estão estudando.

Com base nos dados analisados, não se pode dizer que as atividades de telemarketing sejam atrativas para o trabalhador, visto que parcela significativa dos empregados considera o emprego em call centers como temporário ou ocasional, a não ser no que se refere às suas conveniências particulares, como a jornada curta, que facilita o estudo, ou atividade paralela, ou complementação da renda, entre outros.

Os resultados apresentados indicam a tendência de que as atividades laborais baseadas em informática, mas que são pouco estimulantes, podem ser consideradas como um emprego-trampolim, não exclusivamente no âmbito da atividade de telemarketing, mas especialmente para outros rumos sociais, profissionais ou pessoais aspirados pelos jovens. Os empregados do call center percebem a atividade como temporária, ou seja, adequada à sua situação de momento. Ao mesmo tempo em que "satisfaz" as conveniências dos empregados que são trabalhadores jovens, o emprego nos call centers seria percebido como meio de suprir transitoriamente necessidade materiais. Nessa acepção, a atividade de telemarketing parece configurar uma forma de emprego típica de alguns setores na atualidade, como o trabalho bancário teria sido nos anos 1980.

O ambiente favorável para a emergência desse emprego-trampolim congregaria duas dimensões fundamentais: por um lado, exige um trabalhador jovem, escolarizado, qualificado, criativo e, por outro, oferece baixos salários, poucas possibilidades de ascensão hierárquica, ritmo intenso de trabalho, flexibilidade em horários e preocupações com ergonomia. Condições estruturais do mercado de trabalho influenciam, em grande medida, o aumento da taxa de rotatividade nas empresas, a falta de identificação dos trabalhadores - com a atividade que desempenham e com a sua "categoria profissional” - e a descrença na eficácia do movimento sindical. Essas condições influenciam a reelaboração dos sentidos do estar empregado e do estar desempregado, uma vez que o foco das estratégias que definem o emprego-trampolim não estaria fundado na obtenção da estabilidade, e sim na superação transitória e individual das condições materiais e simbólicas dos atores sociais envolvidos.

O como se trabalha e o quem trabalha apresentam distinções no que se refere ao tipo de telemarketing e ao cliente que contrata o serviço do call center, o que pode significar melhor ou pior qualidade de emprego. Nesse sentido, esse seria um objeto de investigação complexo, que necessita ser abordado em toda sua heterogeneidade. Cabe destacar que os dados obtidos na empresa investigada foram contrastados com dados secundários mais gerais sobre o emprego dos operadores de telemarketing no Brasil, o que permite uma amplitude maior de validade das informações qualitativas obtidas pela pesquisa direta. Nesse sentido, o estudo demonstra sua importância por ressaltar a perspectiva do setor de serviços, espaço em que são bastante evidentes as mudanças no âmbito do trabalho no mundo contemporâneo, instigando a novos estudos nessa área.

(Recebido para publicação em outubro de 2007) (Aceito em julho de 2008)

\section{REFERÊNCIAS}

BATT, Rosemary. Strategic segmentation in front-line services: matching customers, employees and human resource systems. International Journal of Human Resource Management., [S.l.], v.11, n.3, p.540-561, 2000. BIBBY, Andrew. Organising in financial call centres. Discussion Paper. United Kingtom: 30 march, 2000. 
Daniel Gustavo Mocelin,

Luís Fernando Santos Corrêa da Silva

BRAGA, Ruy. Crônicas de autômato: o infotaylorismo como contratempo. In: MACIEL, Maria L.; ALBAGLI, Sarita. Informação e desenvolvimento: conhecimento, inovação e apropriação social. Brasília: UNESCO-IBICT, 2007. p.355-384.

Uma sociologia da condição proletária contemporânea. Tempo Social: revista de Sociologia da USP, São Paulo, v.18, n.1, p.133-152, 2006.

CASTELLS, Manuel. A era da informação: economia, sociedade e cultura. In: São Paulo: Paz e Terra, $\overline{1999}^{\circ}$ v.1

CATTANI, Antonio David. Dicionário crítico sobre traba Iho e tecnologia. 4.ed. Petrópolis: Vozes; Porto Alegre: Ed. da Ufrgs, 2002. 368p.

DEL BONO, Andrea. Call centers, el trabajo del futuro? E caso de estratégia telefónicas S. ${ }^{a}$ (ESTRATEL). Sociologia del Trabajo. Madrid, Siglo XXI Editores, n.39, p.3-61, primavera, 2000.

GLUCKSMANN, Mirian. Call configurations: varieties of call centre and divisions of labour. Work, Employment and Society, Londres, v.18, n.4, p.795-811, 2004.

INFOEXAME. 200 maiores empresas de tecnologia no Brasil. São Paulo, Ed. abril, n.197, ago., 2002. Caderno especial.

KERST, Christian; HOLTGREWE, Ursula. Flexibility and Customer Orientation: where does the slack come from? WORK, EMPLOYMENT AND SOCIETY CONFERENCE. Nottingham, 11-13 sept., 2001. Dat.

KOVÁCS, Ilona. Empresa Flexível: Problemas sociais do pós-taylorismo. In: PEREIRA, Antônio Garcia et al. Globalização: novos rumos no mundo do trabalho. Florianópolis: Ed. da UFSC; SOCIUS, 2001.

\section{TELEMARKETINGANDTHESOCIALANDOCCUPATIONAL PROFLEOFCAШCENTEREMPLOYEES}

\author{
Daniel Gustavo Mocelin \\ Luís Fernando Santos Corrêa da Silva
}

This paper brings research results on workers of a call center, in Porto Alegre, trying to analyze combinedly how one works and who works in telemarketing activities. Call centers are business organizations of telemarketing services. Their operators are workers with high education, compared to Brazilian job market levels, what would point to a professionalization of the activity. Paradoxically, work conditions, characterized by the intensification of labor and low remuneration, but with a demand of medium qualification, influence the strategies and the senses of this job for young workers, defining this as "trampoline job", that just answers to a transitory superation of material and symbolic conditions, and not the search for professionalization and stability, even with the demands of specialized technical knowledge and constant recycling. The characteristics of the sector and the emergency of this new type of worker help to understand labor in the services sector.

KEYwORDS: Sociology of labor, call centers, Porto Alegre, social and occupational profile of workers, job rotation, services.
LARANGEIRA, Sônia M. G. Reestruturação no setor das telecomunicações: inovações tecnológicas, privatizações e desregulamentação: aspectos da experiência internacional. Revista Latinoamericana de Estúdios del Trabajo, Buenos Aires, v.4, n.8, p.159-178, 1998.

A reestruturação das telecomunicações e os sindicatos. Revista Brasileira de Ciências Sociais, São Paulo, v.18, n.52, p.81-86, jun., 2003.

OLIVEIRA, Sirlei M. Reestruturação das Telecomunicacões no Brasil: uma re(visão) das estratégias de gestão da produção e das relações de trabalho na cadeia produtiva (estudo de caso da telefonia fixa em São Paulo - 19902003) 2004. Tese ( Doutorado) - USP, São Paulo, 2004.

ROSENFIELD, Cinara Lerrer. Paradoxos do capitalismo e trabalho em call centers: Brasil, Portugal e Cabo Verde. Caderno CRH: revista do Centro de Recursos Humanos, Salvador, v.20, n.51, p.447-462, set./dez., 2007a.

Construção da identidade no trabalho em call centers: a identidade provisória. In: CONGRESO LATINOAMERICANO DE SOCIOLOGÍA DEL TRABAJO, 5,18 a 20 de abril. Anais... Montevideo, Ur. Dat.

TAYLOR, P.; MULUEY, G.; HYMAN, J.; BAIN, P. Work organization, control and the experience of work in call Centres. Work, Empolyment and Society, Londres, v.16, n.1, mar., p.133-150, 2002.

VENCO, Selma. Telemarketing nos Bancos: o emprego que desemprega. 1999. Dissertação Mestrado (Educação) - Departamento de Ciências Sociais Aplicadas à Educação, UNICAMP. Campinas, 1999.

\section{LETÉLÉMARKETINGETLEPROFLSOCIO}

\section{OCCUPATIONNELDESEMPLOYÉSDES CALLCENTERS}

Daniel Gustavo Mocelin

Luís Fernando Santos Corrêa da Silva

Cet article montre les résultats d'une recherche réalisée auprès des employés d'un call center à Porto Alegre. On essaie d'analyser en même temps comment on travaille et qui travaille dans des activités de télémarketing. Les calls centers sont des entreprises de prestations de services de télémarketing. Ses opérateurs sont des employés dont le niveau de scolarité est élevé si on le compare au niveau du marché de travail brésilien en général, ce qui indiquerait une professionnalisation de l'activité. Paradoxalement les conditions de travail, caractérisées par l'intensification du travail et par une faible rémunération mais exigeant une qualification moyenne, ont une influence sur le sens que les jeunes travailleurs donnent à cet emploi qu'ils finissent par définir comme un "emploi tremplin". Ce travail répond seulement à un besoin matériel et symbolique temporaire et non pas à la quête d'une professionnalisation et d'une stabilité, même si des exigences de connaissances techniques spécialisées et un recyclage constant sont exigés. Les caractéristiques du secteur et le surgissement de ce nouveau type d'employé aident à comprendre le travail dans le secteur de services.

Mots-CLÉs: Sociologie du Travail, call centers Porto Alegre, profil socio occupationnel des travailleurs, rotation des emplois, services. 